\title{
Journal Preprint
}

Environmental impact minimization of reticular structures made of reused and new elements through Life Cycle Assessment and Mixed-Integer Linear Programming

Jan BRÜTTING, Camille VANDERVAEREN

Gennaro SENATORE, Niels DE TEMMERMAN, Corentin FIVET

DOI:

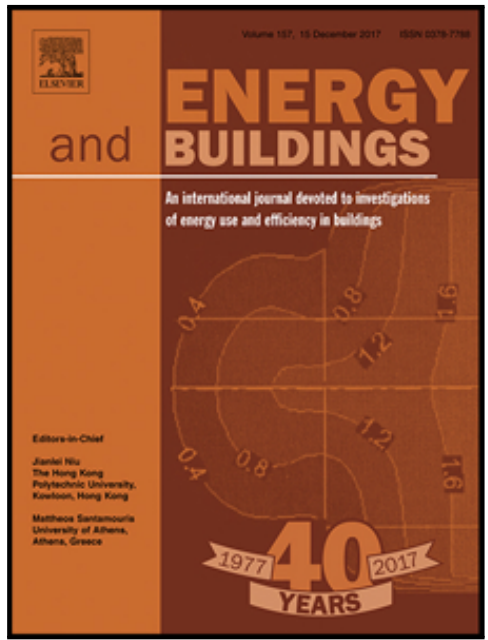

To appear in:

Energy \& Buildings

Received date:

14 October 2019

Revised date:

23 January 2020

Accepted date:

30 January 2020

Please cite this article as: Jan BRÜTTING, Camille VANDERVAEREN, Gennaro SENATORE, Niels DE TEMMERMAN , Corentin FIVET, Environmental impact minimization of reticular structures made of reused and new elements through Life Cycle Assessment and Mixed-Integer Linear Programming, Energy \& Buildings (2020), doi: https://doi.org/10.1016/j.enbuild.2020.109827 


\title{
Environmental impact minimization of reticular structures made of reused and new elements through Life Cycle Assessment and Mixed-Integer Linear Programming
}

\author{
Jan BRÜTTING ${ }^{\mathrm{a}}$, Camille VANDERVAEREN ${ }^{\mathrm{b}}$, Gennaro SENATORE ${ }^{\mathrm{c}}$, \\ Niels DE TEMMERMAN ${ }^{\mathrm{b}}$, Corentin FIVET ${ }^{\mathrm{a}}$
}

\begin{abstract}
Affiliations:
a Structural Xploration Lab, Swiss Federal Institute of Technology (EPFL), Passage du Cardinal 13b, 1700 Fribourg, Switzerland

*Corresponding author: jan.bruetting@epfl.ch (J. Brütting)

b Architectural Engineering, Vrije Universiteit Brussel (VUB), Pleinlaan 2, Brussels, Belgium

c Applied Computing and Mechanics Laboratory, Swiss Federal Institute of Technology (EPFL), Station 18, 1015 Lausanne, Switzerland
\end{abstract}

\begin{abstract}
An important share of building environmental impacts is embodied in load-bearing structures because of their large material mass and energy-intensive fabrication process. To reduce substantially material consumption and waste caused by the construction industry, structures can be designed and built with reused elements. Structural element reuse involves: element sourcing and deconstruction, reconditioning and transport. As these processes also generate environmental impacts, reuse might not always be preferred over new construction. This paper presents a method to design reticular structures with minimal environmental impact made from reused and new elements. The formulation given in this paper is based on a combination of Life Cycle Assessment (LCA) and discrete structural optimization. The LCA carried out in this work accounts for impacts generated from sourcing reclaimed elements to the assembly of the structure. Structural optimization is subject to stress constraints on element capacity and deflection limits for serviceability. Typical loading scenarios are considered. The method is applied to the design of three single-span steel trusses of different topology subject to 100 simulated stocks of reusable elements that have varying cross-sections and lengths. Benchmarks against minimum-weight solutions made solely from recycled steel show that this method produces structures with up to $56 \%$ lower environmental impact. Depending on stock availability, the lowest environmental impact is achieved through a combination of reused and new elements.
\end{abstract}

Keywords: Reuse, environmental impact reduction, Life Cycle Assessment, structural optimization

\section{Highlights}

- Structural optimization with integrated Life Cycle Assessment (LCA)

- Globally optimal element assignments via mixed-integer linear programming

- Environmental impact reduction by up to $56 \%$ for structures made of reused elements

- Statistical analysis carried out through varying 100 stock configurations

- Combining reused and new elements results in least environmental impact structures 


\section{Introduction}

\subsection{Construction sector environmental impact}

From 2000 to 2017 global annual steel and cement demand has doubled to 2.5 gigatons [1]. It has been estimated that in 2017 extraction, manufacturing and use of materials by the construction sector has been responsible for $11 \%$ of the overall energy- and process-related $\mathrm{CO} 2$ (carbon dioxide) emissions worldwide [1]. Construction and demolition waste is the largest stream by volume in the European Union totaling a third of all waste produced yearly [2]. In next decades, growth and densification of urban areas will lead to the demolition, transformation, and new construction of a great amount of residential, industrial, and public buildings and the necessary infrastructure [3]. For these reasons, there is a need for improved design methods and construction techniques to help reducing structures material usage and environmental impact as well as construction and demolition waste.

\subsection{Structural design and component reuse}

Load-bearing systems contribute an important share of the environmental impact embodied in buildings [4], [5] because of their large mass and energy-intensive fabrication. Conventional strategies to reduce this impact consist in designing material-efficient structures or in using low-impact materials. However, despite current efforts, the environmental impact of the construction sector remains an urgent concern and new means must be found to reduce it [6]. Another strategy consists in extending the service life of structural components by reusing them. Reuse avoids sourcing raw material, it requires less process energy and therefore causes lower $\mathrm{CO} 2$ emissions [7]-[9]. In addition, reuse reduces waste and maintains the value of a product [10]. The reuse of structural elements entails a particular challenge in structural design: the design is governed by available element characteristics, e.g. material, cross-section, and dimensions [11, p. 180]. Depending on the element stock, to design and build a structure made only of reused elements might not be feasible. For example, there might not be enough elements of a certain length and cross-section available that fit within a required layout. In other cases, structures made from reused elements might be oversized with respect to weight optimized structures made of newly produced elements [12]-[14].

Reuse of structural components requires extra processing for deconstruction, reconditioning (e.g. cleaning and sandblasting elements) and transport, which exerts additional environmental impact. On the other hand, production of new structural components requires sourcing and energy-intensive processing of primary and secondary (recycled) material.

\subsection{Outline}

Drawing on previous developments [12], [13], this paper presents a novel computational method that produces least environmental impact (EI) structures made from a combination of reused and new elements. The method combines 
structural optimization and Life Cycle Assessment (LCA) through mixed integer linear programming. Inputs consists in generated element stocks, which represent elements sourced from deconstructed buildings, as well as the target structural typology. Outputs are the structural system with global minimum EI, the optimal assignment of elements to the structure, and the optimal ratio between reused and new elements (Figure 1). Optimization constraints relate to structural ultimate limit states (e.g. element capacity) and serviceability limit states (e.g. deflection limits). The method has been implemented to design reticular structures. The examples presented in this paper focus on steel trusses because their reuse is usually easier than for other materials. Steel structures are often dismountable through reversible connections and their components with standard cross sections and grades can be cut and reshaped. In addition, the capacity of steel elements can be assessed through on-site and off-site visual, acoustic or load testing [7].

A literature review on reuse, structural optimization and environmental impact assessment is given in Section 2 . The method formulation is explained in Section 3. The relevance of the proposed method is illustrated via the design of three single span trusses of different topology (Section 4). Discussion of results, conclusions and future works are in Sections 5 and 6.

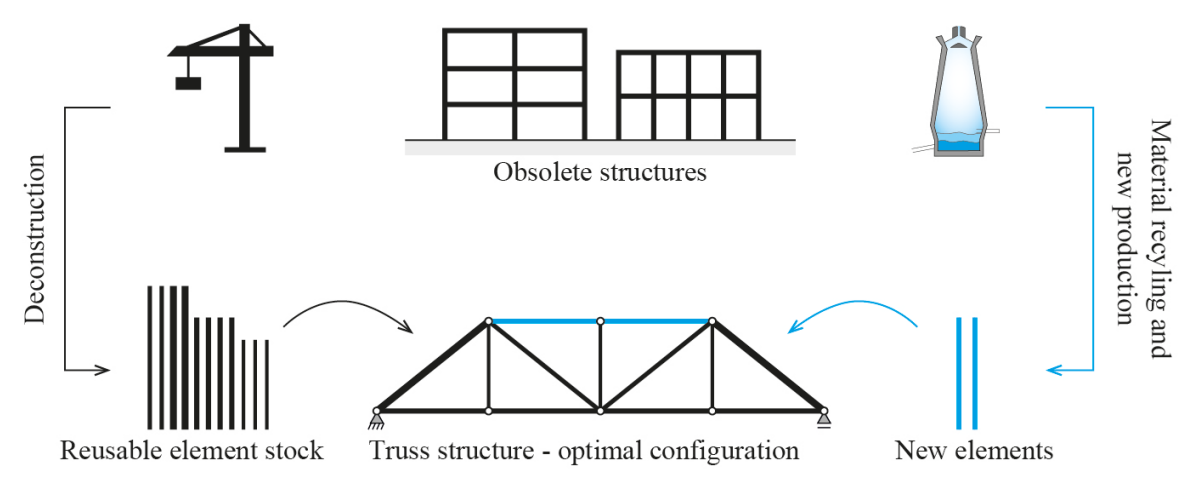

Figure 1: Optimal design of structures from reused and new elements (primary and secondary steel)

\section{Literature review}

This study combines three fields of research: reuse in structural design (Section 2.1), environmental impact assessment of reused products (Section 2.2), and methods that combine environmental impact minimization and structural optimization (Section 2.3). Research gaps identified from the literature survey that support the motivation of this work are given in Section 2.4. Following Addis [7, p. 200] the term 'reuse' is understood as "putting objects back into use, either for their original purpose or a different purpose without major prior reprocessing to change their physical characteristics, in order that they do not enter the waste stream. While it does not include reprocessing, it might involve some reconditioning." 


\subsection{Reuse in structural design}

Reuse of structural components was employed by ancient Egyptians, Greeks and Romans. For example, the reuse of stones and bricks from ruins was often preferred to the cutting of new ones [7]. A few building structures which include reused elements also exist in contemporary architecture [7], [9], [15], [16]. An iconic example is the 2012 London Olympic Stadium whose roof truss is made of 2,500 tons of second-hand pipeline tubes, which amount to $20 \%$ of the whole steel used in the roof structure [15].

Aside from isolated examples, reuse of structural components is currently very limited in the construction sector. For example in the UK it has been estimated from surveys that only $5-7 \%$ of the light and heavy structural steel sections were reused in 2012 [17]. Densley Tingley et al. [18] and Dunant et al. [19] highlighted the main barriers to the adoption of reuse in practice: supply chain dynamics, costs, limited demand, traceability and quality certification. Structural assessment of reclaimed components can overcome uncertainties regarding capacity [7], as done for the London Olympic Stadium [15]. In addition, Ness et al. [20] and Luscuere [21] present methods to create so-called material passports to store information of structural components for multiple service lifespans. As identified in [18], [19], [22], the implementation of databases for element stocks and the establishment of a market is essential for the broad adoption of reuse in the construction sector.

Little research regarding the process of designing structures from reused elements can be found in literature. Conventional structural design assumes that members are fabricated according to design specifications (e.g. member cross-sections and lengths) and in unlimited quantity. Conversely, when reusing structural elements, the design is governed by stock element characteristics, e.g. cross-sections and element dimensions [11]. Pongiglione and Calderini [14] present the design of a railway station roof made of truss modules reclaimed from industrial buildings and combined with new steel elements. In their study, reusing the reclaimed modules required also new elements for both architectural and structural reasons. It was shown that the structure obtained this way, could save $30 \%$ of the embodied energy and equivalent carbon compared to a solution made of new elements only. Fujitani and Fujii [23] developed evolutionary algorithms for the weight optimization of frames from a stock of one-time available cross-sections. However, the availability of discrete element lengths was not considered. Bukauskas et al. [24] applied heuristic algorithms to fit a stock of wood logs to statically determinate trusses. Brütting et al. [13] developed a method for the optimal design of truss structures from a stock of elements accounting for discrete cross-sections and lengths. This method was successfully applied to the conceptual design of a train station roof made of elements reclaimed from electric pylons [12]. 


\subsection{Life cycle assessment of reused products}

The studies cited in previous section indicate that design though reuse is gaining momentum. However, reuse might not always reduce the structure environmental impact [25]. A common method to quantify and compare the environmental impact of products is Life Cycle Assessment (LCA). LCA accounts for all substances exchanged with the environment (e.g. consumed resources and emissions) during production, usage and dismissal of products. LCA quantifies a product environmental impact (EI) through environmental damage indicators such as climate change, fossil resource depletion and human health. A product EI is not directly related to the amount of materials it is made of, but rather to the characteristics of these materials and the damage those materials cause to the environment. Moreover, EI not only depends on the final product but on the processes that occur to it during its life cycle. As a result, two similar products with different production processes and usages will have a different EI.

LCA can estimate the EI of secondary products resulting from recycling or reuse. In a comparative LCA study of reused and recycled steel products, a potential reduction of greenhouse gas emissions and water consumption for reused steel products was estimated by Yeung et. al. [26]. LCA for a reused product is challenging because it requires the allocation of EI over different uses, for which different methods exist [27]. The choice of an allocation method is generally left to the LCA practitioner. International and European standards [28], [29] as well as the International Reference Life Cycle Data System (ILCD) handbook [30] only provide a framework for comparing LCA studies rather than giving guidelines for the selection of an appropriate allocation method [31]. The selection of suitable allocation methods is part of a larger debate regarding the definition of environmental sustainability [32]. There are three main approaches to allocate a product environmental impact over different uses [27]. The first approach, 100:0 (also called cut-off), considers the impact avoided by the use of secondary material in the production stage, but does not give any credit for future recycling or reuse. The second approach, 0:100, does not consider the impact avoided using secondary goods in production, but accounts for future recycling or reuse. The third approach, 50:50, allocates the impact equally over the production and end-of-life stages. The approach taken for this study, the cut-off method, is explained in more detail in Section 3.3.

\subsection{Structural optimization with integrated LCA}

Optimization is often employed to improve the efficiency of structures. Three main categories exist for reticular structures: element sizing, geometry and topology optimization. The optimization objective varies depending on the application. Commonly used in practice is weight minimization but only partially contributes to lower the structure environmental impact through reduction of the energy and carbon embodied in the material mass [33]. However, LCA accounts for the whole structure life cycle, which for instance also includes transport, waste and usage (Section 2.2). Exemplary studies integrating LCA into structural geometry optimization illustrate methods to produce vaults [33] and long span roofs [34] 
with minimum total life cycle energy by balancing the structure embodied energy with the energy required to heat or cool the space covered by the structure. The combination of LCA and structural optimization involving reuse has been investigated by Brütting et al. [12], [13]. However, in that study the structure embodied energy was the only environmental indicator accounted for.

\subsection{Research gaps and own contribution}

Designing and building structures through reuse is gaining momentum in research and practice. However, methods that integrate the design of structures from reused elements with LCA analysis are still lacking. For this reason, this work provides a new optimization method 1) to design a structure from a stock of available elements, 2) to minimize its environmental impact, and 3) to benchmark it against minimum-weight solutions.

\subsection{Comparison with previous work}

The original contribution of this work consists in three extensions of the method given in [12], [13]: 1) the advancement to a cutting-stock approach, 2) the possibility to combine reused and new elements to obtain hybrid solutions, and 3) a refined LCA with sensitivity analysis of LCA parameters (e.g. impact factors). In previous work [12], [13], the assignment of a stock element to a position in the structure was 1-to-1, i.e. one stock element could only be used once and for a specific structure member. In this case, if a long stock element is used for a short member, the assignment results in a large cut-off length (waste). Instead, this new work allows partitioning of stock elements into multiple structure members (cutting-stock), thus one stock element can be used at multiple positions. Consequently, the solution space is largely increased, cut-off can be reduced and results in terms of EI reduction can be improved. The previous approach and the method described in this paper are compared in Appendix D. Cutting-stock has also been studied by Bukauskas et al. [24]. Different from their heuristic, the present formulation is based on a combinatorial optimization technique (mixedinteger linear programming) which produces globally optimal solutions. Since the solutions are global optima, LCA allows for a rigorous benchmark between structures made from reused and those made of new elements. In addition, the formulation given in this work allows combining reused and new elements, which can result in solutions of lower EI compared to structures made of reused elements only.

The LCA adopted in this work and its integration into the optimization method is outlined in section 3.3. In this paper, the EI is expressed in terms of environmental points calculated with the 'ReCiPe' Life Cycle Impact Assessment (LCIA) method [35] rather than in terms of embodied energy or equivalent carbon as in previous work [12], [13]. 


\section{Methodology}

\subsection{Benchmarking process}

Section 3.2 gives the formulation of environmental impact (EI) minimization of steel truss structures made from reused and new elements. The inputs of the optimization are a structure layout (geometry and topology), applied loads, serviceability requirements (i.e. deflection limits) as well as a predefined element stock. The output is the structure with globally minimum EI, the optimal partitioning of stock elements, their assignment to the structure, and the optimal ratio between reused and new elements, denoted as 'reuse rate' (RR).

The total EI of the structure is the sum of all process EIs occurring from sourcing over manufacturing to assembling the structure elements (cradle-to-gate). These process EIs are computed through Life Cycle Assessment (LCA) (section 3.3). Starting from an obsolete building which serves as a material bank, two routes 'Reuse' and 'New' are distinguished. The 'Reuse' route involves that a building structure is deconstructed, elements are refurbished and eventually reused in the optimized truss structure. The 'New' route considers that a demolished building structure is turned into steel scrap and then new truss members are produced from a mix of primary and secondary (recycled) steel. It is assumed that both reused and new elements have the same technical life span, i.e. all processes occurring after the assembly of the optimized structure ('gate') are assumed identical and thus excluded from the LCA.

The optimization method further provides results for structures made of reused $(R R=100 \%)$ or new elements $(R R=0 \%)$ only. Because the LCA assumes equal performance of new and reused elements, it is possible to benchmark the minimum EI solution with optimal RR against the two extremes $(\mathrm{RR}=0 \%$ or $100 \%)$. This benchmarking may be carried out for one or multiple structure layouts with identical design requirements (e.g. span, loading). Further, it can be employed for one element stock (e.g. based on a real case) or for many stocks with varying element cross-sections and lengths. Investigating many stock configurations indicates the influence of the stock on the structure EI, mass and optimal RR. In addition, varying different LCA and stock related parameters (e.g. transport distances or process impact factors) gives insight on the influence of these parameters on obtained results.

\subsection{Element assignment and structural optimization}

\subsubsection{Assumptions}

The term member denotes a bar at a certain position in the structure. The term element denotes both, the components available for reuse from a stock and those from new production. Stock elements are characterized by material properties (density, elasticity, strength), cross-section dimensions (area and perimeter), length, origin (to estimate transport distances) and availability. Stock elements can be cut into one or more pieces (cutting-stock) but they cannot be extended. New elements are always adequately dimensioned for their position as a truss member, without constraint on their length 
or availability. For the case studies (Section 4), hollow cross-section profiles are assumed to be joint welded. Joint structural design is beyond the scope of this work. The assumption taken here is that the environmental impact of the joints is similar for the reuse and the new production case and hence it does not influence the benchmarking significantly.

\subsubsection{Combinatorial problem}

The optimization method is illustrated on a simple planar truss shown in Figure 2(a). The structure consists of $m=13$ members. Figure 2(b) shows a set $\boldsymbol{R}$ of 15 stock elements. Each stock element is presented as a gray bar. Cross-sections and lengths of stock elements are predefined. The elements available from new production are instead represented as light blue bars and constitute the set $\boldsymbol{N}$. The selection of cross-sections for new elements is constrained within a given finite inventory (e.g. standard steel sections). New elements can be produced with any length.

(a)
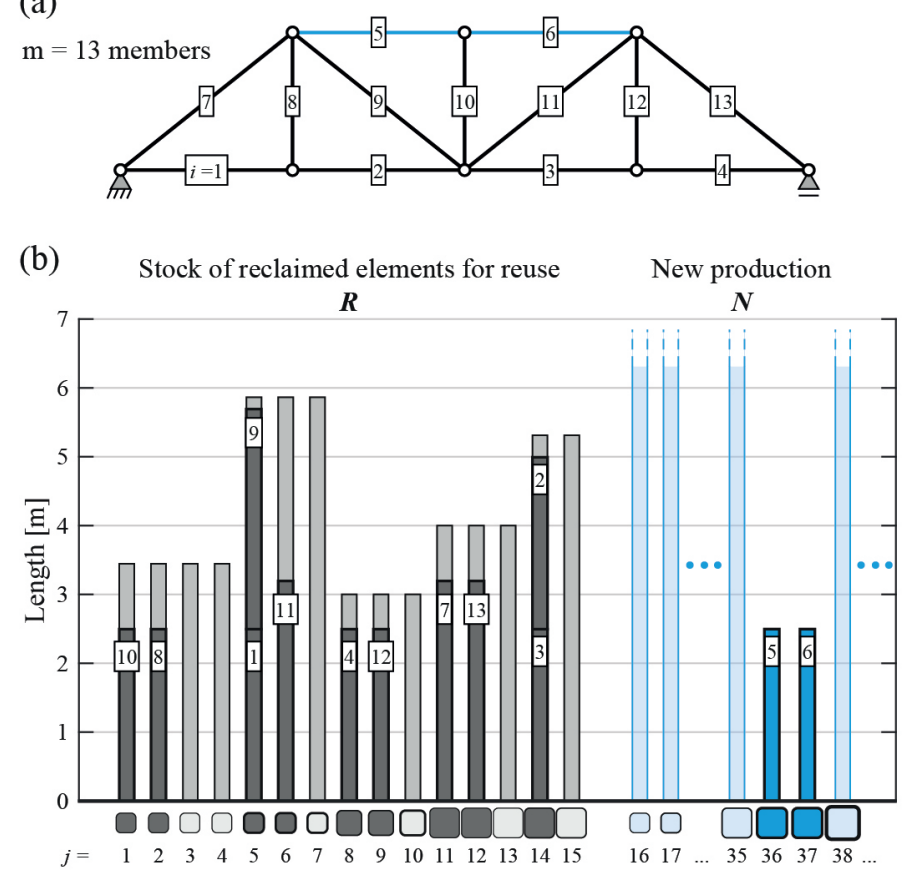

Figure 2: Reuse of stock elements in a truss structure. (a) Structure system, (b) stock (grey bars), new elements (blue bars)

The $i$ index refers to the member numbering of the structure. The $j$ index identifies available stock and new elements. Stock elements portions that are assigned to the structure are indicated by dark grey bars in Figure 2(b). The member index labels indicate the assignment of a specific cross-section to the position $i$ in the structure. The cut-off length of stock elements is represented by light grey bars above dark grey ones. Similarly, dark blue bars indicate new elements assigned to the structure. New elements are adequately dimensioned, i.e. they do not have any cut-off length.

The assignment of a portion of a stock element $j$ or of a new element $j$ at member position $i$ is represented via a binary design variable $t_{i, j}$ which is an entry of the assignment matrix $\boldsymbol{T} \in\{0,1\}^{m \times s}$, where $s$ is the size of the stock $\boldsymbol{R}$ plus the size of the set of elements available from new production $N$. The value of a binary assignment variable is: 
$t_{i, j}= \begin{cases}1 & \text { if member } i \text { is either cut out from stock element } j \in \boldsymbol{R} \text { or produced new with cross-section } j \in \boldsymbol{N} \\ 0 & \text { if member } i \text { is neither cut out from stock }\end{cases}$

Another set of binary design variables $y_{j \in R} \in\{0,1\}$ is defined to model the state when structural members are cut from a stock element:

$y_{j}= \begin{cases}1 & \text { if one or more members are cut out from stock element } j \in \boldsymbol{R} \\ 0 & \text { if no member is cut out from stock element } j \in \boldsymbol{R}, \text { i.e. element } j \text { remains unused }\end{cases}$

For each member $i$, either one stock element $j$ is reused or one new element $j$ is produced, as defined by the constraint:

$$
\sum_{j=1}^{s} t_{i, j}=1 \forall i
$$

The use of stock element $j \in \boldsymbol{R}$ for one or more members is constrained by the available length:

$$
\sum_{i=1}^{m} t_{i, j} l_{i}^{\prime} \leq y_{j} l_{j} \forall j \in \boldsymbol{R}
$$

The length of member $i$ is denoted by $l_{i}$, i.e. the distance between the end nodes of member $i$. The length of stock element $j$ is denoted by $l_{j}$. When a member cannot be cut from any stock element (e.g. because of unavailable force capacity or length), a new and adequately sized element is produced in order to satisfy Eq. (1). For example, this was the case for members 5 and 6 in the illustrative example of Figure 2.

\subsubsection{Objective function}

The objective function is formulated as:

$$
\min _{\boldsymbol{y}, \boldsymbol{T}} \sum_{j \in \boldsymbol{R}} c_{j} \cdot y_{j}+\sum_{j=1}^{s} \sum_{i=1}^{m} c_{i, j} \cdot t_{i, j}
$$

The objective value is the sum of two 'cost' indices. The constant $c_{j}$ is the cost to source and process stock element $j \in \boldsymbol{R}$. The constant $c_{i, j}$ is the cost to manufacture or install element $j$ (reuse or new) at position $i$. With the introduction of constants $c_{j}$ and $c_{i, j}$, the objective function is general and can be employed for minimizing the structure weight, embodied energy, waste, carbon emissions, or monetary cost. In this work, the objective is to minimize the structure environmental impact (EI) and the constants $c_{j}$ and $c_{i, j}$ are obtained through life cycle assessment (Section 3.3).

\subsubsection{Structural optimization}

The objective function (Eq. 3) and constraints (Eq. 1) and (Eq. 2) are linear with respect to the binary design variables $\boldsymbol{y}$ and $\boldsymbol{T}$. The formulation is complemented by structural optimization constraints such as equilibrium of forces, geometric compatibility between nodal displacements and element deformations, deflection limits (serviceability limit state), stress and member buckling constraints (ultimate limit state). As shown in [12], [13] these conditions can also be formulated as linear constraints. Hence, the complete problem of designing structures from reused and new elements can be formulated 
as a mixed-integer linear programming (MILP) problem. MILP problems can be solved to global optimality, for instance via branch-and-bound techniques [36]. In this work, the optimization problem was solved using Gurobi 8.1 [37].

\subsection{Environmental impact calculation}

The constants $c_{j}$ and $c_{i, j}$ in the objective function (Eq. 3) (Section 3.2.3) are the 'cost' indices to source and process stock elements $j \in \boldsymbol{R}$, and to manufacture or install an element $j$ (new or reused) at member position $i$. To minimize the EI of a structure, these constants combine all process impacts generated during material sourcing (e.g. demolition or deconstruction), processing and final assembly of the structure. Process impacts are obtained through an attributional LCA modelling. Unlike consequential modelling, which accounts for the consequences of a decision, attributional modelling depicts the actual system by identifying the flows of matter and energy it initiates along the life cycle stages [30]. This section presents the LCA goal and scope, inventory and impact assessment.

\subsubsection{Goal and scope}

The goal of the LCA carried out in this work is to define the environmental impact $E I^{\text {Pro }}$ of each process during the life cycle of either a reclaimed or a new steel element that is used as a truss member. All environmental impacts $E I^{\text {Pro }}$ are summed to obtain the life cycle impact of using an element at a specific position in the structure. A functional unit is defined for each process and per process metric, e.g. surface area $\left(\mathrm{m}^{2}\right)$ to sandblast. Each process $E I^{\text {Pro }}$ is expressed in a single environmental impact score calculated with the ReCiPe Endpoint $(\mathrm{H}) \mathrm{V} 1.12$ impact method which combines environmental indicators to account for damages to human health, ecosystems and resource availability [35]. The assessment starts with the impact of sourcing materials from an obsolete structure and ends with that for assembling the optimized truss at the new site, i.e. from EN 15978 stage A1 to A5 [28]. The use and end of life of the truss (stages B and C) are expected to be identical for all compared solutions and thus excluded from the assessment. Different to conventional assessment, the inventory of material sourcing stage A1 considered in this work includes the deconstruction or demolition of an obsolete building structure from which the elements are reclaimed. This expanded system boundary is required to carry out a rigorous comparison between the 'New' and 'Reuse' cases. In this work, a cut-off (100:0) approach is employed. This way, the matter and energy flows saved by employing recycled or reused content in the production of steel bars are accounted for. At the contrary, the matter and energy flows that would be avoided at the endof-life by further recycling or reusing contents are omitted (Section 2.2).

\subsubsection{Inventory of processes}

Figure 3 gives the flowchart of the material flow analysis (MFA) and the system boundary considered in this work. The MFA includes all processes and material flows considered in the LCA and is drawn from a synthesis of technical reports and publications [26], [38], [39]. The MFA distinguishes new and reused cases. In the 'New' case, new members are 
produced from recycled steel and the process inventory includes demolition of buildings, preparation of the steel scrap prior recycling, loading and transport [38]. The production of new steel sections is assumed to be made through an electricarc furnace and hot rolling. In the 'Reuse' case, the deconstruction process consists in the following tasks: opening existing connections, hoisting elements, preparation (e.g. sorting), and loading of elements on trucks as specified in [38]. Then, elements are transported to a reconditioning facility and are sandblasted (cleaning and de-rusting). In both cases, new and reuse, the elements are transported to a fabrication workshop, where they are calibrated, welded into trusses, degreased, and powder coated. The trusses are finally transported to the construction site and assembled. Unused stock elements are not part of the system boundary and therefore do not contribute to the total environmental impact of the truss. These unused elements could be stored and used in other projects.

Each process in the MFA diagram is associated with an inventory of resources and emissions. This life-cycle inventory was made using LCA software SimaPro 8 [40] and process data from Ecoinvent 3.1 'default allocation' database [41] (see Appendix A). This database considers average supply market, unconstrained market conditions, and economic allocation of multiple outputs and includes operational and embodied impacts. Since this LCA includes embodied EI of machines and services, it refines previous studies by Brütting et al. [13], which only included the operational energy due to machining (e.g. fuel consumption). Missing process data in Ecoinvent was collected from other data sources including Gabi [42] and other publications (cf. data source in Table 1). Machine operation hours for demolition and deconstruction processes are extracted from [38] which gives detailed information regarding the machine type required for common deconstruction processes, required working hours and fuel consumption per kg of reclaimed steel. Although in [38] the considered location is Canada, the execution of these operations is supposedly equivalent in the European context of this work. 


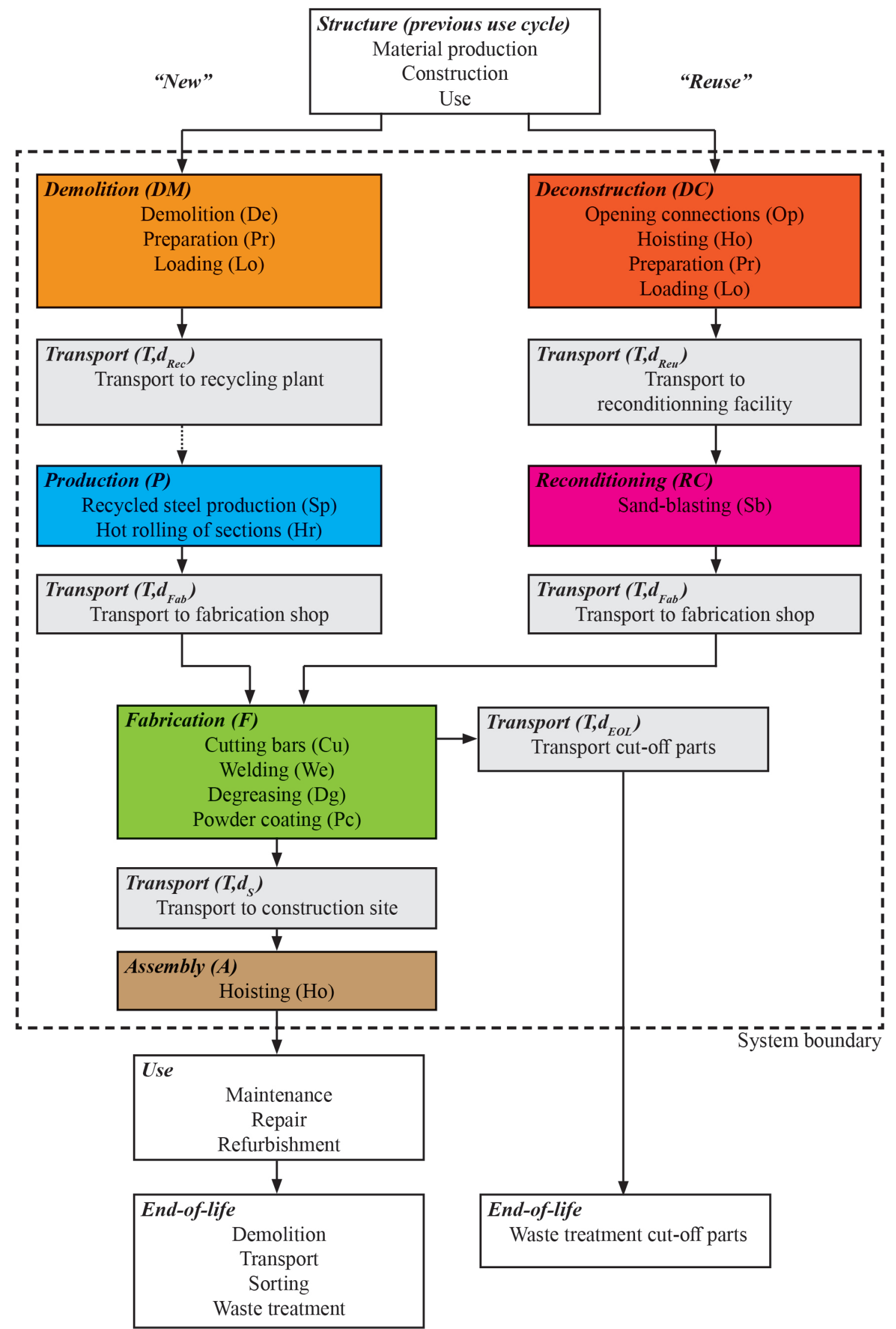

Figure 3: LCA processes and system boundary 


\subsubsection{Impact assessment}

Table 1 gives the $E I^{\text {Pro }}$ factors in terms of ReCiPe points for all processes shown in Figure 3. The data source is given in the rightmost column of Table 1.

Table 1: Environmental impacts of New and Reuse case processes

\begin{tabular}{|c|c|c|c|c|c|}
\hline & Proce & Process name & Metric & $E I^{P r o}$ in $10^{-3} \times \mathrm{ReCiPe}$ points /metric Data source & \\
\hline \multirow[t]{4}{*}{ Demolition } & DM & Total & {$[\mathrm{kg}]$} & 4.19 & \\
\hline & De & Demolition & {$[\mathrm{kg}]$} & 2.60 & 1) \\
\hline & $\operatorname{Pr}$ & Preparation & {$[\mathrm{kg}]$} & 1.06 & 1) \\
\hline & Lo & Loading & {$[\mathrm{kg}]$} & 0.53 & 1) \\
\hline \multirow[t]{3}{*}{ Production } & $\mathbf{P}$ & Total & [kg] & 102.49 & \\
\hline & $\mathrm{Sp}$ & Steel production & {$[\mathrm{kg}]$} & 71.80 & 2) \\
\hline & $\mathrm{Hr}$ & Hot rolling & {$[\mathrm{kg}]$} & 30.68 & 2) \\
\hline \multirow[t]{5}{*}{ Deconstruction } & DC & Total & [kg] & 18.62 & \\
\hline & Op & Opening connections & [kg] & 9.98 & 1) \\
\hline & Ho & Hoisting & [kg] & 6.80 & 1) \\
\hline & $\operatorname{Pr}$ & Preparation & [kg] & 1.71 & 1) \\
\hline & Lo & Loading & [kg] & 0.13 & 1) \\
\hline \multirow[t]{2}{*}{ Reconditioning } & $\mathbf{R}$ & Total & {$\left[\mathrm{m}^{2}\right]$} & 185.36 & \\
\hline & $\mathrm{Sb}$ & Sand blasting & {$\left[\mathrm{m}^{2}\right]$} & 185.36 & 3) \\
\hline \multirow[t]{5}{*}{ Fabrication } & $\mathbf{F}$ & Total & $\mathrm{N} / \mathrm{A}$ & N/A & \\
\hline & $\mathrm{Cu}$ & Cutting both ends & [m] circumference & 25.97 & 2) \\
\hline & We & Welding both ends & [m] circumference & 25.97 & 2) \\
\hline & $\mathrm{Dg}$ & Degreasing & {$\left[\mathrm{m}^{2}\right]$} & 1.56 & 2) \\
\hline & $\mathrm{Pc}$ & Powder coating & {$\left[\mathrm{m}^{2}\right]$} & 411.03 & 2) \\
\hline \multirow[t]{2}{*}{ Assembly } & A & Total & {$[\mathrm{kg}]$} & 6.80 & \\
\hline & Ho & Hoisting & [kg] & 6.80 & 1) \\
\hline Transport & $\mathbf{T}$ & Transport by truck & {$[\mathrm{kg} \cdot \mathrm{km}]$} & 0.018 & 2) \\
\hline
\end{tabular}

The $\operatorname{cost} c_{j}$ in Eq. 3 is the environmental impact $E I_{j}$ for reusing stock element $j \in \boldsymbol{R}$ and is equal to the sum of all impacts associated with sourcing element $j$ (deconstruction DC, reconditioning $\mathrm{R}$ ) as well as with transportation (T) (see Figure 3 and Table 1 for nomenclature of superscripts):

$$
E I_{j}=E I_{j}^{D C}+E I_{j}^{T, d R e u}+E I_{j}^{R}+E I_{j}^{T, d F a b}
$$

For example, the environmental impact associated with deconstruction to reclaim element $j$ is the product of its mass (material density $\rho_{j} \cdot$ cross-section area $a_{j} \cdot$ length $l_{j}$ ) with the process impact factor for deconstruction $E I^{D C}($ Table 1 , $[$ ReCiPe points/kg]):

$$
E I_{j}^{D C}=\rho_{j} \cdot a_{j} \cdot l_{j} \cdot E I^{D C}
$$

The environmental impact $E I_{i, j}$ (equals cost $c_{i, j}$ in Eq. 3) of using element $j$ (new or reused) at position $i$ in the truss is the sum of all impacts in reference to member position $i$. For new elements $(j \in N)$, those impacts are related to demolition (D) of an obsolete building, new element production (P), fabrication (F), assembly (A), and to all intermediate transport (T):

$$
E I_{i, j \in N}=E I_{i, j}^{D}+E I_{i, j}^{T, d R e c}+E I_{i, j}^{P}+E I_{i, j}^{T, d F a b}+E I_{i, j}^{F}+E I_{i, j}^{T, d S}+E I_{i, j}^{A}
$$

For example, the impact to produce member $i$ (with member length $l^{\prime}{ }_{i}$ ) with section $j \in N$ is expressed as:

$$
E I_{i, j}^{P}=\rho_{j} \cdot a_{j} \cdot l_{i}^{\prime} \cdot E I^{P}
$$


For a reused element, the impacts of sourcing element $j \in \boldsymbol{R}$ are independent of member position $i$ and are already contained in $E I_{j}$. For this reason, only fabrication (F), transport (T, $\left.d_{S}\right)$ to site, assembly (A) and transport of cut-off waste ( $\left.\mathrm{T}, d_{E O L}\right)$ are considered in $E I_{i, j \in R}$ :

$$
E I_{i, j \in \boldsymbol{R}}=E I_{i, j}^{F}+E I_{i, j}^{T, d S}+E I_{j}^{T, d E O L}
$$

Surface treatment impact is independent of the element source (reuse or new). For example, the impacts of degreasing $(\mathrm{Dg})$ and powder coating $(\mathrm{Pc})$ are calculated per surface area as the product of the $j^{\text {th }}$ element cross-section circumference and the truss member length $l_{i}$.

\section{Application}

The method outlined in Section 3 is applied to three single-span truss structures of different layout. The structural systems and load cases are defined in Section 4.1. Optimization results obtained for a single stock are given in Section 4.2. Sensitivity of results to element stock composition is evaluated by carrying out the optimization process for 100 different stocks (Section 4.3). Each stock has a different inventory of element cross-sections and lengths. Finally, a parametric study is carried out to quantify the importance of selected LCA impact factors as well as of the main assumptions related to the case studies (Section 4.4).

\subsection{Structural system definition}

Figure 4 shows three simply supported trusses of 20 m span: A) a Howe truss, B) a pitched Pratt truss, and C) a Warren truss with a circular bottom chord. These designs are selected because they are commonly used in practice. All members are pin-jointed. It is assumed that trusses of the same type are spaced with $6.20 \mathrm{~m}$ distance to form a roof. The construction site is assumed to be in Germany.

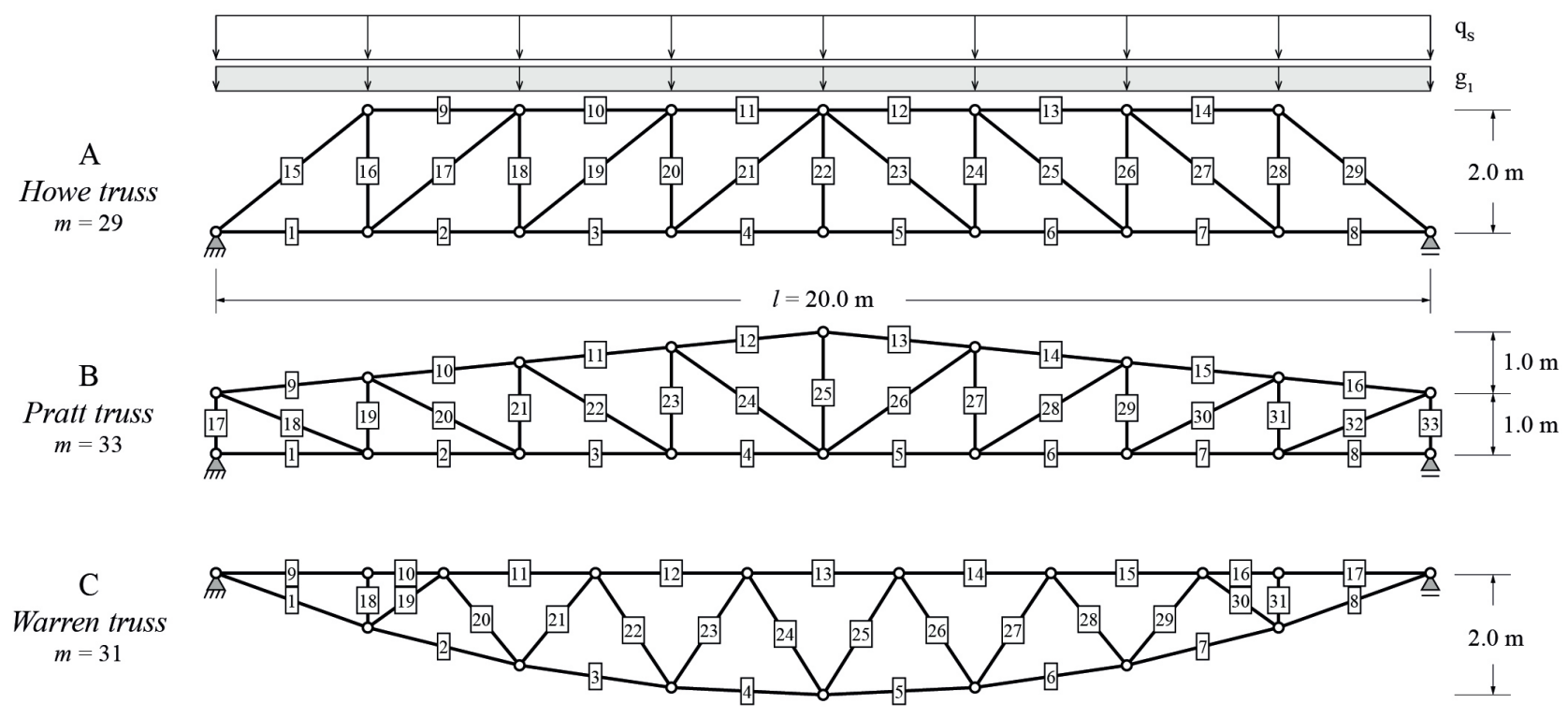

Figure 4: Roof truss structure case studies 
The structure self-weight $g_{0}$ depends on the element assignment and is taken into account via the structural optimization. A uniformly distributed dead load $g_{l}$, resulting from a roof cover, is applied to the top chord nodes. Similarly, a snow load $q_{s}$ is applied over the full span. Two load combinations are considered: one for ultimate limit state (ULS) and one for serviceability limit state (SLS). SLS deflection limits are set to $l / 300=67 \mathrm{~mm}$. Table 2 summarizes load magnitudes and combination cases.

Table 2: Load cases and combinations

\begin{tabular}{lll}
\hline Load case & Load magnitude & Description \\
\hline$g_{0}$ & Dependent on assigned elements & Taken into account via structural optimization \\
$g_{I}$ & $1.86 \mathrm{kN} / \mathrm{m}$ & Dead load $\left(0.30 \mathrm{kN} / \mathrm{m}^{2}\right)$ \\
$q_{s}$ & $4.03 \mathrm{kN} / \mathrm{m}$ & Live load, snow $\left(0.65 \mathrm{kN} / \mathrm{m}^{2}\right)$ \\
\hline Load combination & & \\
\hline ULS & $1.35 \cdot\left(\mathrm{g}_{0}+\mathrm{g}_{1}\right)+1.50 \cdot \mathrm{q}_{\mathrm{s}}$ & Design loads \\
SLS & $1.00 \cdot\left(\mathrm{g}_{0}+\mathrm{g}_{1}\right)+1.00 \cdot \mathrm{q}_{\mathrm{s}}$ & Characteristic loads \\
\hline
\end{tabular}

In practice, truss members are usually clustered in groups that share a common cross-section. To simulate a realistic design and ensure a feasible fabrication of the trusses, element assignment is subject to 'fabrication' constraints. These extra constraints ensure that: 1) adjacent bottom and top chord members are fabricated in pairs to avoid cutting, and 2) cross-section width variation of adjacent members is limited to $\pm 10 \mathrm{~mm}$ to ease joint fabrication. Further information regarding the application of these constraints is given in Appendix B. The influence of these constraints on solution optimality is discussed in Section 4.4 .

\subsection{Optimization for a given stock}

\subsubsection{Stock definition and new steel sections}

Figure 5(a) shows a stock with nine different element types available for reuse. Each type is characterized by crosssection, length and number of available elements $n$ per type. In this case study, the stock elements are square hollow sections (SHS) of standard sizes as given in EN 10219-2 [44].

(a) Reuse - Stock elements

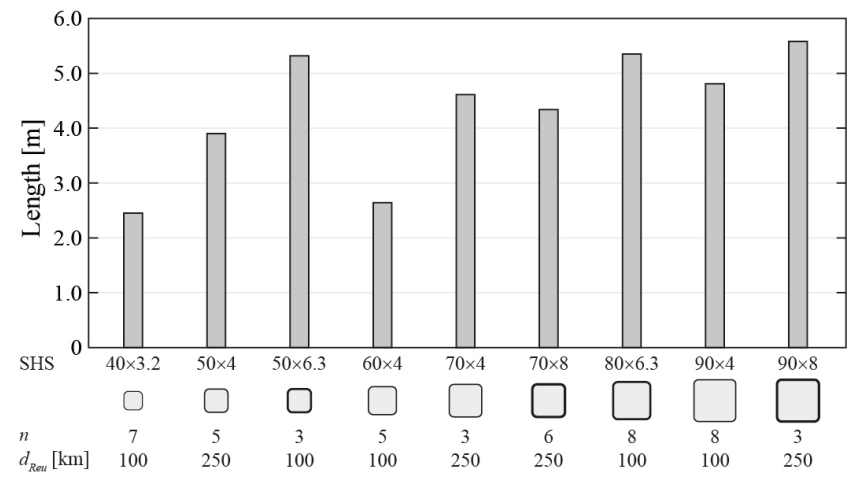

(b) New production - Element cross sections

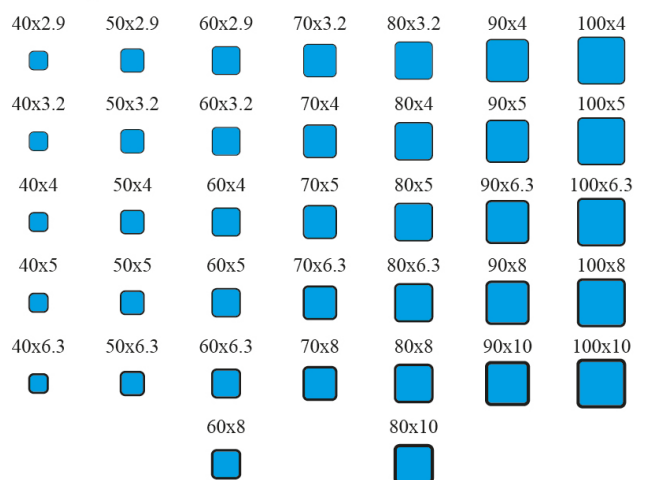

Figure 5: (a) Stock of available element types and transport distances. (b) Available cross-sections from new production 
The material is steel of grade S235 with a density of $7850 \mathrm{~kg} / \mathrm{m}^{3}$, a Young's modulus of $210 \mathrm{GPa}$, and a yield strength of $235 \mathrm{MPa}$. However, for reused elements a strength reduction of $10 \%$ is assumed in order to simulate uncertainties on the element capacity and material degradation. The stock elements are assumed to originate from two different buildings, which are located at a distance $d_{R e u}$ of $100 \mathrm{~km}$ and $250 \mathrm{~km}$ from the reconditioning workshop. New elements are available in the standard SHS cross-sections listed diagrammatically in Figure 5(b). The distance $d_{R e c}$ from the demolition site to the production plant is assumed to be $100 \mathrm{~km}$. Reused and new elements are transported to the fabrication workshop over a distance $d_{F a b}$ of $20 \mathrm{~km}$ and from there to the building site over a distance $d_{S}$ of $20 \mathrm{~km}$. Cut-off waste is transported for $20 \mathrm{~km}$ from the fabrication site to the recycling plant $\left(d_{E O L}\right)$.

\subsubsection{Results}

In the following, the ratio between the mass of the structure made from reused elements over its total mass is termed reuse rate (RR). The objective is the minimization of the structure environmental impact (EI) considering three scenarios: 1) all members are from new production $(\mathrm{RR}=0 \%), 2)$ the optimal $\mathrm{RR}$ is obtained through optimization, and 3 ) all members are reused elements $(\mathrm{RR}=100 \%)$. Figure 6 shows the optimal element assignment for the Pratt truss in all three scenarios. New elements are indicated in blue and reused elements in black. The cross section is indicated through line thickness. Labels indicate the member index and the assigned cross-section size. As shown in Figure 6(a), when the structure is made of elements from new production only, it is possible to use small cross sections in the bottom tension chord and in the diagonals. The top chord is made of larger cross-sections because of member buckling constraints. Figure 6(c) shows the optimal assignment for the case with reused elements only. In this case, the bottom chord members have larger cross sections with respect to case (a). Figure 6(b) shows the Pratt truss with minimum EI obtained for an RR of $88 \%$. This hybrid solution features the same cross-section size as the reuse-only case (c) for the top chord members. However, new production permits the design of a lighter bottom chord and diagonals with respect to case (c). Note that for cases (b) and (c) stock elements are partitioned to be assigned to up to three members in the structure (cutting-stock). Similar results are obtained for the Howe and Warren trusses (see Appendix C). 
(a) Pratt New $R R=0 \% \quad E I=64.8$
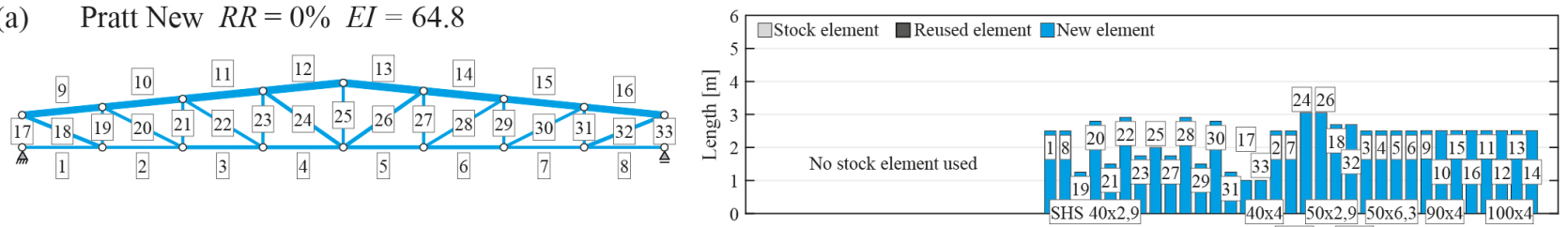

(b) Pratt Optimal $R R=88 \% E I=35.4$
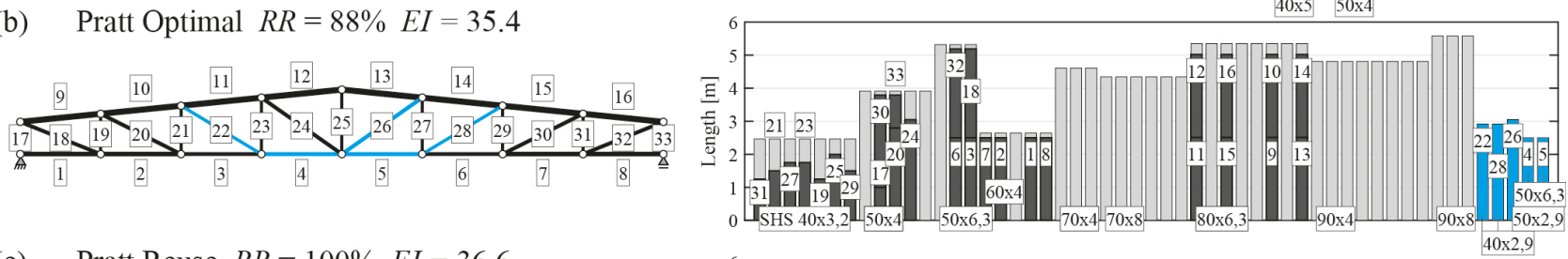

(c) Pratt Reuse $R R=100 \% \quad E I=36.6$
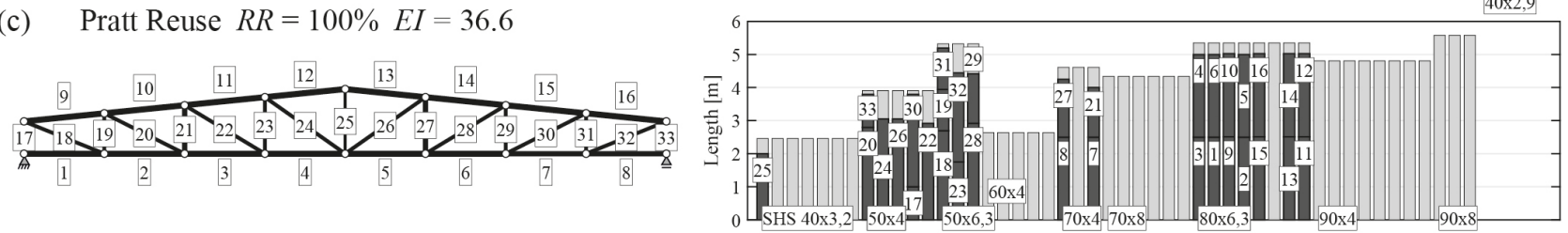

Figure 6: Pratt truss optimal assignment: (a) the structure made of elements from new production, (b) the optimal 'hybrid' structure with minimal environmental impact, and (c) the structure with reused elements only

Table 3 gives the results for all scenarios and truss types. Structures made of new elements only have the lowest mass (476 to $505 \mathrm{~kg}$ ), but the highest EI (61.4 to $64.8 \mathrm{ReCiPe}$ points). Structures made of reused elements only have a substantially higher mass (up to $784 \mathrm{~kg}$ ) but a much lower EI (31.5 to 38.0 ReCiPe points). For the Howe and Pratt truss, the minimum EI is achieved for a reuse rate of $93 \%$ and $88 \%$ respectively. The Warren truss with a reuse rate of $100 \%$ has the lowest EI compared to all other cases. The optimal Howe and Pratt truss structures have a smaller mass than for their respective $100 \%$ reuse rate cases, meaning that oversizing is reduced in hybrid solutions. Capacity utilization expresses the ratio of a member axial force over the admissible force (including buckling). System mass is inversely proportional to mean member capacity utilization. The new element structures have the highest mean capacity utilization but do not reach a full utilization because of the discrete nature of the cross-section sizing. The SLS deflection limit of 67 $\mathrm{mm}$ is respected for all cases.

Table 3: Optimization results for the three trusses and for different reuse rates

\begin{tabular}{|c|c|c|c|c|c|c|c|c|c|c|c|}
\hline \multirow[t]{2}{*}{ Scenario } & \multirow[t]{2}{*}{ Layout } & \multirow[t]{2}{*}{ Reuse rate } & \multirow[t]{2}{*}{$\begin{array}{l}\text { Number } \\
\text { of reused } \\
\text { elements }\end{array}$} & \multirow{2}{*}{$\begin{array}{l}\text { System } \\
\text { mass } \\
{[\mathrm{kg}]}\end{array}$} & \multirow{2}{*}{$\begin{array}{l}\text { Reused } \\
\text { steel } \\
\text { mass } \\
{[\mathrm{kg}]}\end{array}$} & \multirow{2}{*}{$\begin{array}{l}\text { New } \\
\text { steel } \\
\text { mass } \\
{[\mathrm{kg}]}\end{array}$} & \multicolumn{2}{|c|}{$\begin{array}{l}\text { Mass used Waste } \\
\text { stock } \\
\text { elements }\end{array}$} & \multirow{2}{*}{$\begin{array}{l}\text { Mean } \\
\text { capacity } \\
\text { utilization } \\
{[\%]}\end{array}$} & \multirow{2}{*}{$\begin{array}{l}\text { Max } \\
\text { deflection } \\
{[\mathrm{mm}]}\end{array}$} & \multirow{2}{*}{$\begin{array}{l}\text { EI } \\
\text { [ReCiPe points] }\end{array}$} \\
\hline & & & & & & & {$[\mathrm{kg}]$} & {$[\mathrm{kg}]$} & & & \\
\hline \multirow[t]{3}{*}{ New } & Howe & $0 \%$ & - & 476 & - & 476 & - & - & $72 \%$ & 37 & 62.9 \\
\hline & Pratt & $0 \%$ & - & 492 & - & 492 & - & - & $69 \%$ & 44 & 64.8 \\
\hline & Warren & $0 \%$ & - & 465 & - & 465 & - & - & $66 \%$ & 46 & 61.4 \\
\hline \multirow[t]{3}{*}{ Optimal } & Howe & $93 \%$ & 27 & 633 & 591 & 42 & 718 & 127 & $55 \%$ & 32 & 36.6 \\
\hline & Pratt & $88 \%$ & 28 & 615 & 541 & 74 & 594 & 53 & $59 \%$ & 37 & 35.4 \\
\hline & Warren & $100 \%$ & 31 & 693 & 693 & 0 & 736 & 43 & $47 \%$ & 30 & 31.5 \\
\hline \multirow[t]{3}{*}{ Reuse } & Howe & $100 \%$ & 29 & 700 & 700 & - & 890 & 190 & $49 \%$ & 28 & 38.0 \\
\hline & Pratt & $100 \%$ & 33 & 784 & 784 & - & 859 & 75 & $47 \%$ & 31 & 36.6 \\
\hline & Warren & $100 \%$ & 31 & 693 & 693 & - & 736 & 43 & $47 \%$ & 30 & 31.5 \\
\hline
\end{tabular}




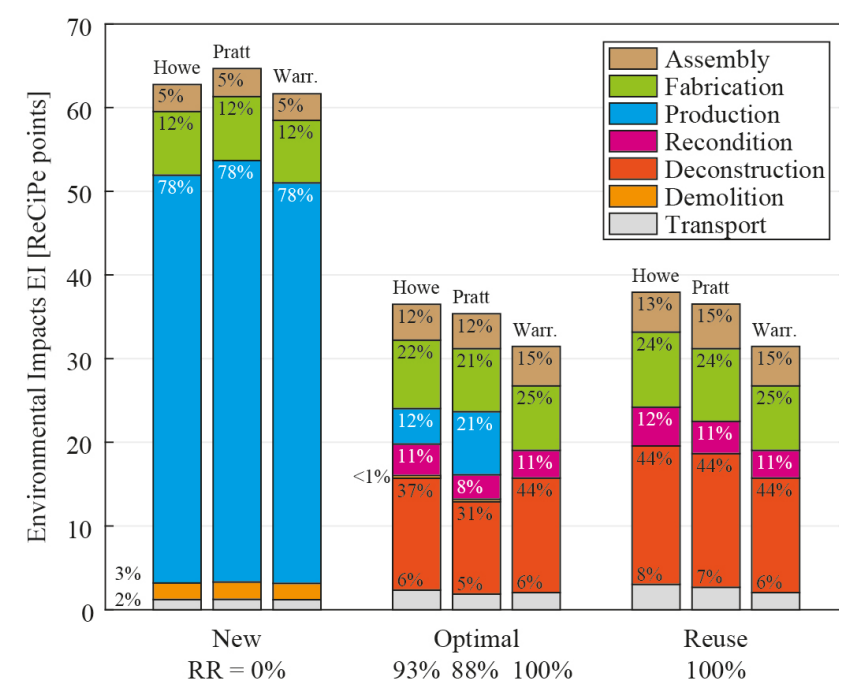

Figure 7: Shares of environmental impact for each structure and scenario

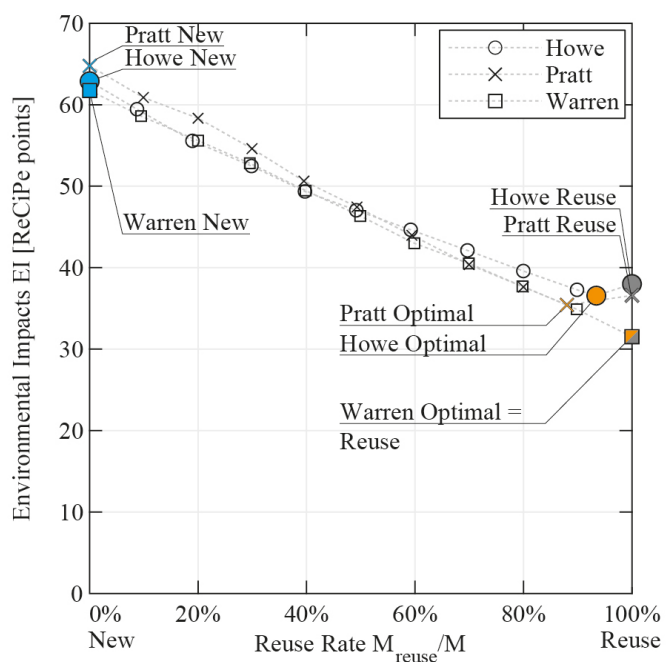

Figure 8: Optimization results vs reuse rate

The bar chart in Figure 7 shows the contribution of individual LCA processes to the EI of each truss type and for each scenario. For new structures, the production of elements (steel production and hot-rolling, blue bars in Figure 7) has the largest EI share (78\%), followed by fabrication (in green, 12\%). The demolition (in orange, 3\%) and transport (in grey, 2\%) shares are comparatively small for new element structures. For structures made from reused elements only, deconstruction has the largest EI share (in red, 44\%), followed by fabrication (in green, 24\%) and reconditioning (in purple, $12 \%$ ). For the optimal Howe and Pratt trusses, new production and deconstruction impacts are counterbalanced to achieve the overall minimum EI.

To investigate the correlation between EI and RR, different optimizations have been carried out by varying the upper bound on the reuse rate in $10 \%$ steps from RR $\leq 10 \%$ to $\mathrm{RR} \leq 100 \%$. Figure 8 plots the EI as a function of RR obtained for these intermediate solutions. For all three structures, the plot shows an approximately linear decrease of the EI when the RR increases.

\subsection{Optimization for statistically simulated stocks}

\subsubsection{Stock definition}

In practice, the composition of a stock (element cross sections and lengths) is subject to element availability which depends on deconstruction and supply chain dynamics. To quantify the influence of stock availability on the outcome produced by the optimization method, the same case studies defined in section 4.1 are simulated for 100 randomly generated stocks. The inventory is made by 13 SHS cross-sections. Each time a different stock is generated, four crosssection types are randomly removed from the inventory i.e. elements with these cross-sections will not be available for reuse. For each element type $j \in \boldsymbol{R}$, the number of elements $n$ per type is a random integer between 2 and 8 . The length $l_{j}$ 
per element type is drawn from a uniform distribution between $1.00 \mathrm{~m}$ and $8.00 \mathrm{~m}$. The assumption regarding the distance from the demolition site and the fabrication workshop is the same as that defined in section 4.2.1. The stock used in section 4.1 is one of these 100 randomly generated stocks and it is shown by the bar chart in Figure 9.

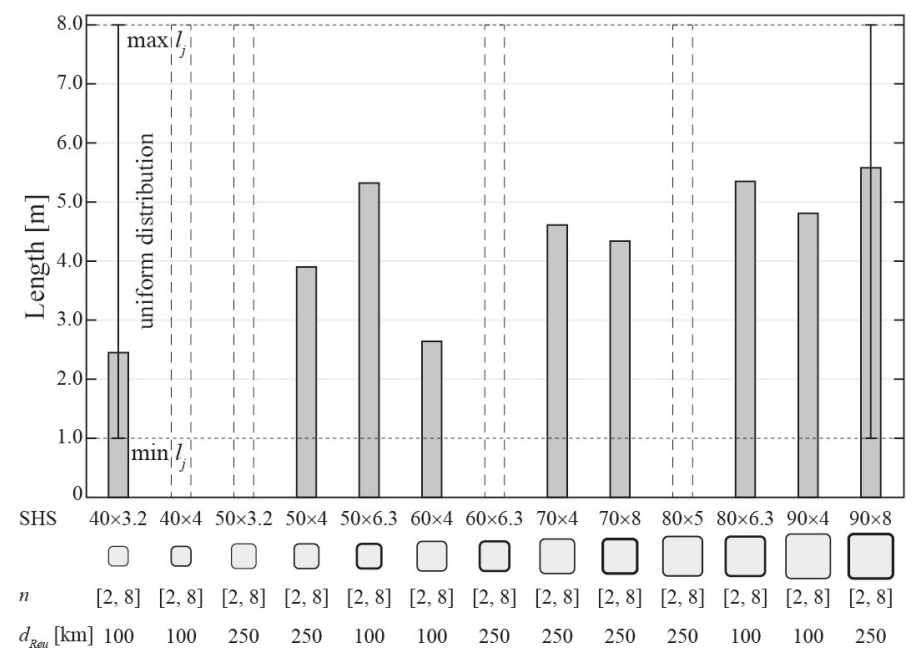

Figure 9: Definition and bounds of stock configurations

\subsubsection{Results}

The scatter plot in Figure 10 contains solutions obtained from 100 randomly generated stocks for each of the three truss types. Each data point is the result obtained for a truss type and one stock. Figure 10(a) plots the structure environmental impact (EI) against reuse rate (RR). For the same dataset, Figure 10(b) plots the total structure mass against RR and Figure 10(c) the mean element capacity utilization against RR. Blue data points (Figure 10, left) correspond to structures made from new elements only $(\mathrm{RR}=0 \%)$. Black data points (Figure 10, right) correspond to structures made from reused elements only (imposed RR of 100\%). Yellow data points in Figure 10 are solutions obtained for unconstrained RR between $0 \%$ and $100 \%$ which have the least EI per stock.

The box plots (Figure 10, right) indicate the distribution of overlapping data points obtained at an RR of $100 \%$. There are two box plots, one is for the unconstrained case i.e. no bound has been set for the RR (yellow) and the other is for solutions obtained by setting RR to $100 \%$ (black). The central line of the boxes indicates the median, the lower and upper edges are the $25 \%$ and $75 \%$ quartile respectively. Whiskers indicate the minimum and maximum values. 
(a)

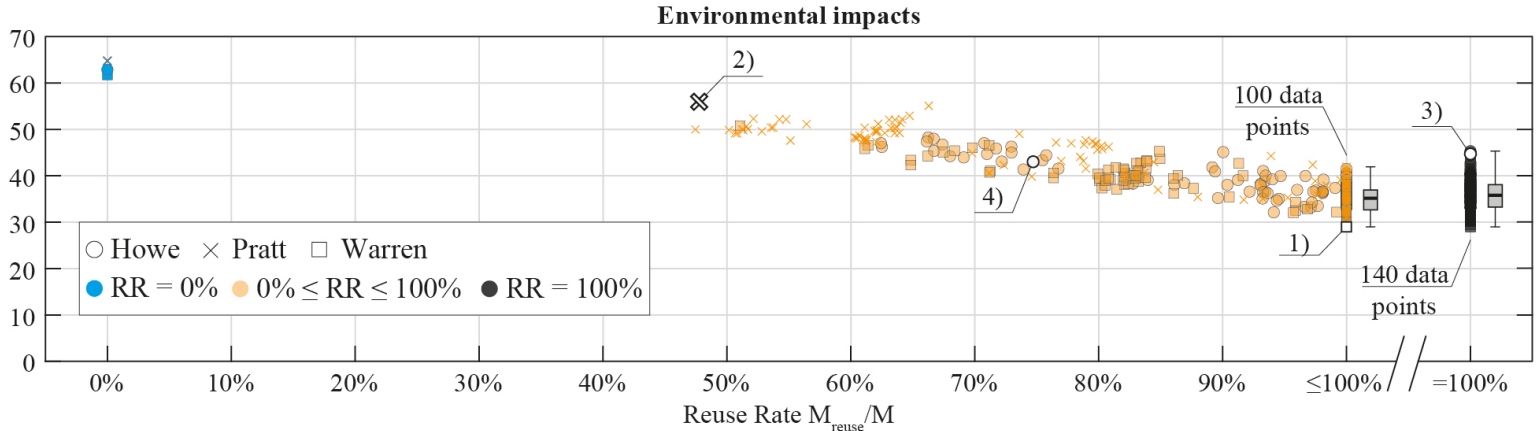

(b)

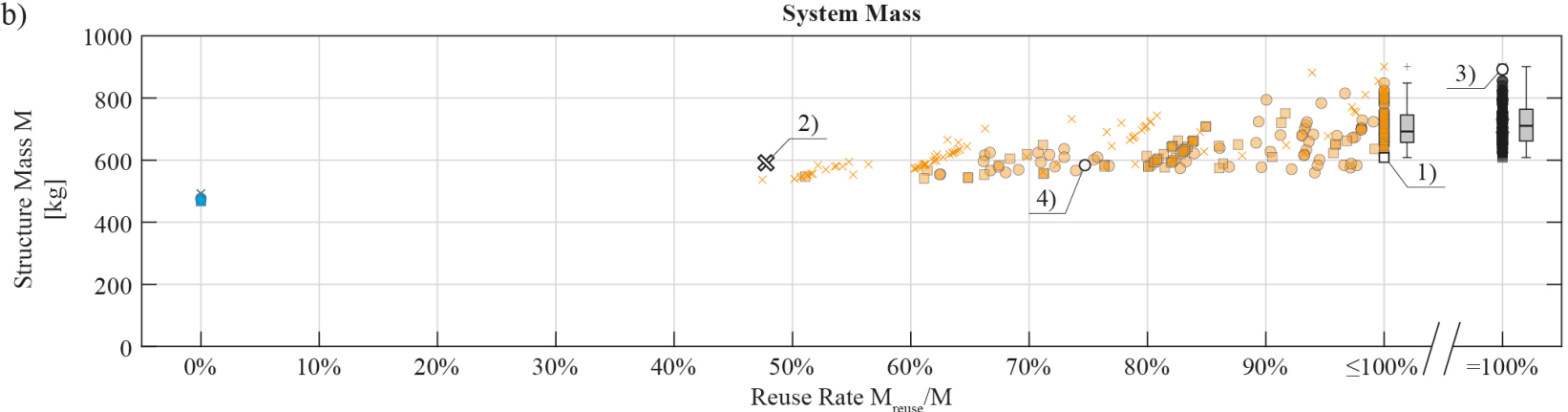

(c)

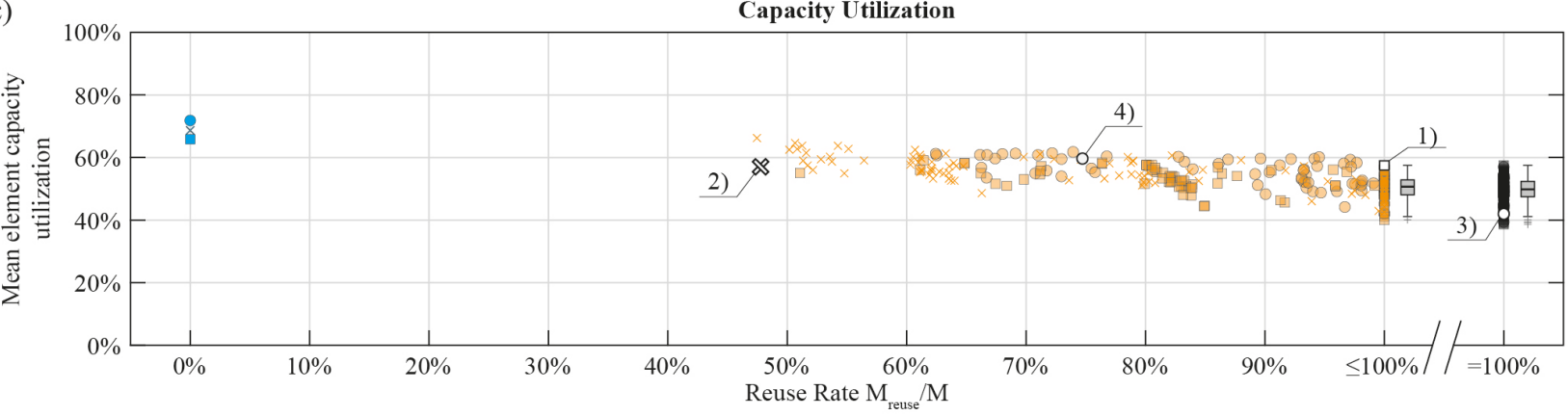

Figure 10: Environmental impact (a), structure mass (b) and element capacity (c) for solutions obtained from 100 stocks per truss type and for different reuse rate bounds. Labelled data points 1)-4) refer to solutions shown in Figures Figure 11 to Figure 14

From Figure 10(a) it can be concluded that, generally, the structure EI decreases when the RR increases (as observed in section 4.2). The solutions made from new elements only $(\mathrm{RR}=0 \%)$ have an average $\mathrm{EI}=63.2 \mathrm{ReCiPe}$ points (blue). Out of the 300 solutions with $0 \% \leq \mathrm{RR} \leq 100 \%$ (yellow data points), 166 have an EI $\leq 40$ ReCiPe points and 61 have an $\mathrm{EI} \leq 35 \mathrm{ReCiPe}$ points thus reducing their EI by $37 \%$ and $44 \%$ with respect to the solutions made from new elements only. On the contrary, the structure mass increases as the RR increases (Figure 10b) which results in a lower mean element capacity utilization due to oversizing as shown in Figure 10(c).

In agreement to what was observed in section 4.2 , an RR of $100 \%$ does not necessarily result in least EI solution for a given stock (Figure 8). Depending on the stock, a reuse rate lower than $100 \%$ might result in the least EI solution. In some cases, depending on the availability of element properties, a high RR may not be feasible at all, e.g. if the stock elements cannot satisfy force capacity requirements or their length is too short to be assigned to the truss members. Out of the 300 unconstrained solutions (yellow data points) only 100 solutions are obtained at an RR of 100\%. The other 200 solutions 
have an RR between $47 \%$ and $<100 \%$. When an RR of $100 \%$ is imposed (black data points), only 140 of the 300 stock configurations are feasible. In other words, for the other 160 stocks no solution at RR $=100 \%$ can be obtained. Solution infeasibility per truss type is: $35 \%$ for Howe truss, $73 / \%$ for Pratt truss, and 52\% for Warren truss. This result suggests that, for this case study and stock configurations, the Howe truss is the most suitable type to be built with reused elements, which is possibly due to the simplicity of its layout.

Four notable solutions are indicated with labels 1) to 4) in Figure 10. Solution 1) has the least EI of all data points and is a Warren truss with an EI of 29.0 ReCiPe points and weight of $608 \mathrm{~kg}$. This solution is represented in more detail in Figure 11. The corresponding stock consists of three element types (SHS $40 \times 3.2,60 \times 6.3$ and $70 \times 8$ ) with a minimum length of $5.50 \mathrm{~m}$. This allows partitioning the elements into truss members with almost no waste. In addition, the crosssections of these three element types fit well the force distribution in the truss: SHS $40 \times 3.2$ elements are used in diagonals which experience comparatively smaller forces, SHS $60 \times 6.3$ elements are used in the tension chord which experience higher forces and SHS $70 \times 8$ elements are assigned to the top chord to prevent buckling.

1)

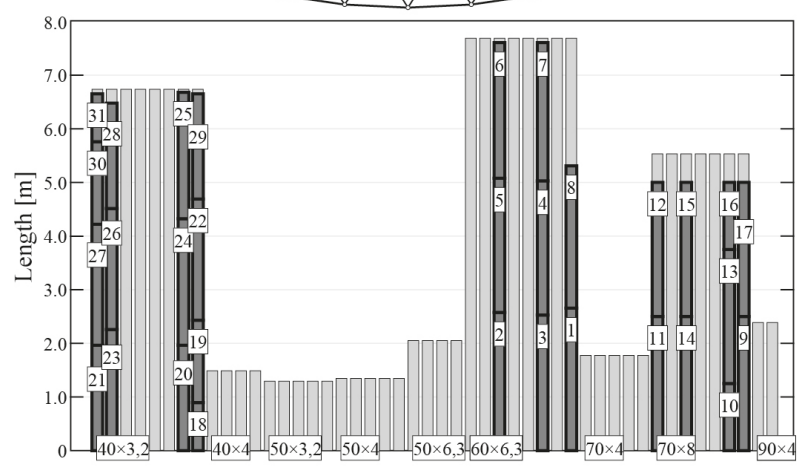

Figure 11: Warren truss with overall minimum $E I=29.0$ ReCiPe pts, $M=$ $608 \mathrm{~kg}, \mathrm{RR}=100 \%$

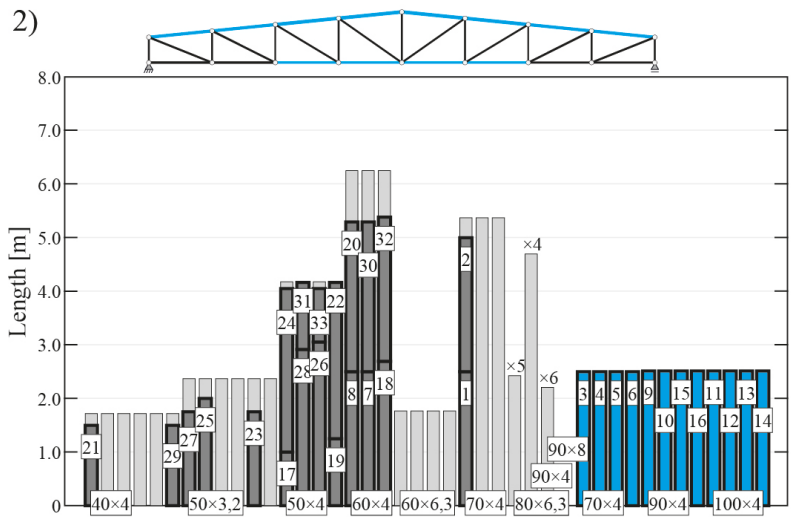

Figure 12: Pratt truss with overall maximum EI $=56.0$ ReCiPe pts, $M=591 \mathrm{~kg}, R R=48 \%$ For some unused stock element types, the availability is abbreviated (e.g. $\times 5$ )

The solution with largest EI and unconstrained RR is labeled 2) and it is shown in more detail in Figure 12. Solution 2) is a Pratt truss with an EI of 56.0 ReCiPe points and a mass of $591 \mathrm{~kg}$ at an RR of $48 \%$. In this case, the stock does not have elements with the required length and capacity for the highly stressed top and central bottom chord members. Those members are consequently assigned from new production (indicated in blue in Figure 12).

The minimum EI solution with the highest mass is labeled 3) in Figure 10(b). Solution 3) is a Howe truss with $892 \mathrm{~kg}$ and an EI of 44.7 ReCiPe points. This solution is represented in more detail in Figure 13. Note that for 3), an RR of $100 \%$ is imposed. This means that all members are made from reused elements. Since this stock contains mostly elements with large cross-sections, the structure mass is large. Instead, for the same stock as in 3) but with unconstrained RR, an element assignment with lower EI and mass (3\% and 34\% respectively) can be achieved when some members are replaced with 
elements from new production as shown by solution 4) in Figure 14. Different to 3), the top chord members in 4) are made from new elements (indices 9 to 14) with smaller cross-sections. This shows that enforcing an RR of $100 \%$ can cause member oversizing and thus might not result in the lowest EI for a given stock.

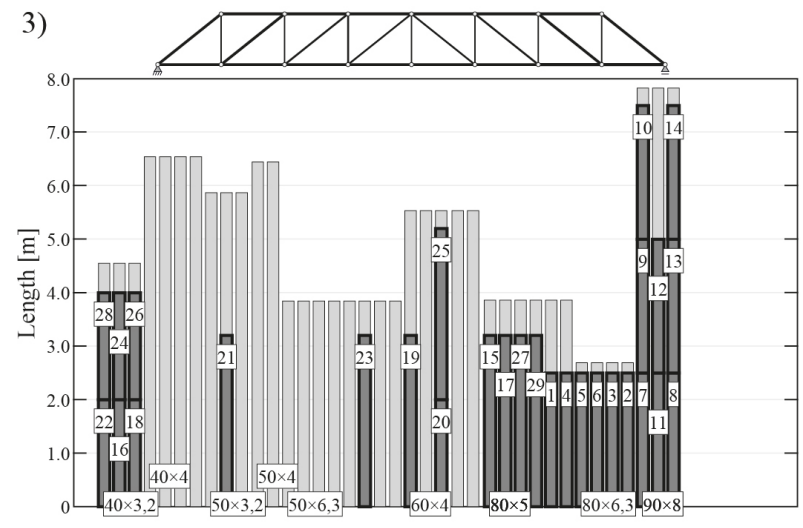

Figure 13: Howe truss with overall maximum mass $M=892 \mathrm{~kg}, E I=$ 44.7 ReCiPe pts and RR set to $100 \%$

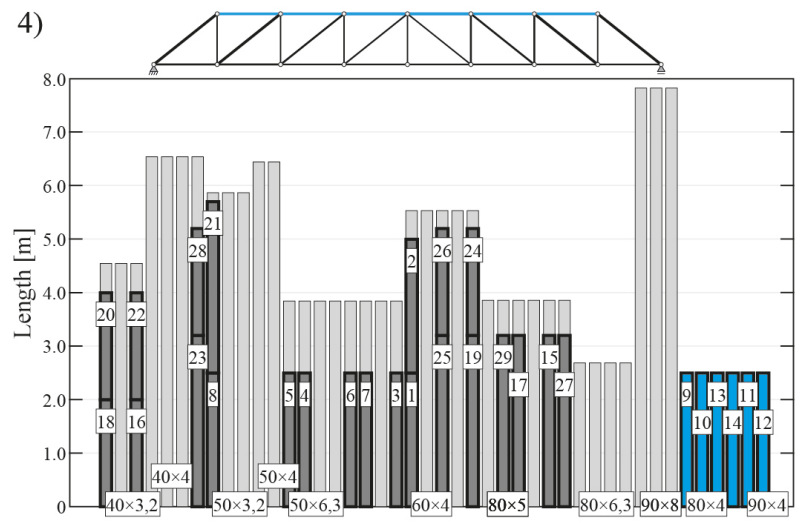

Figure 14: Howe truss subject to same stock as 3) but at unconstrained $R R=74,7 \%, E I=43$ ReCiPe pts and $M=584 \mathrm{~kg}$
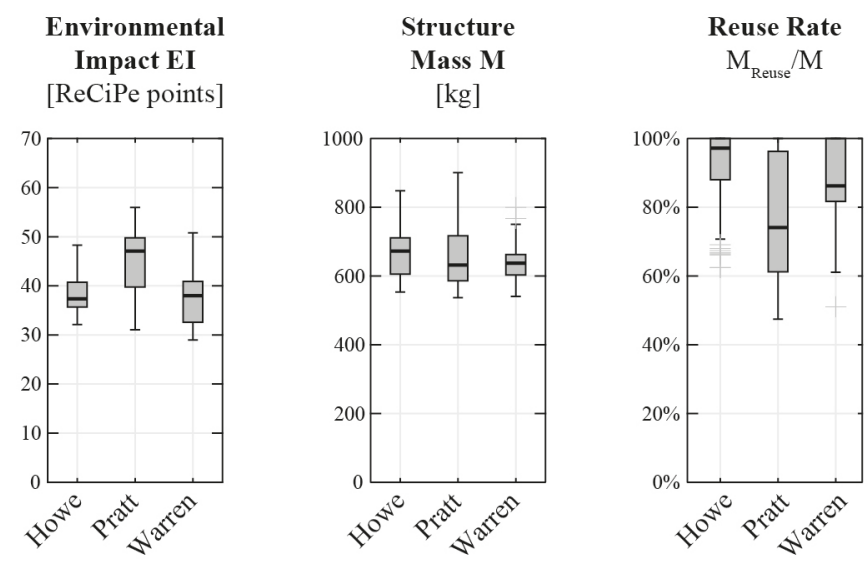

Figure 15: Solutions obtained with unconstrained $R R, 0 \%<=R R<=100 \%$ (yellow data points in Figure 10)

The boxplots in Figure 15 show the range of environmental impact (EI), mass (M) and reuse rate (RR) for all solutions with unconstrained RR (yellow data points in Figure 10). The whisker lengths are set to be at most the same length as the interquartile range $(25 \%-75 \%)$. Data points beyond the whiskers are marked as 'outliers' $(+)$. Solutions of type Howe and Warren have a median EI of approximately $37 \mathrm{ReCiPe}$ points (central lines of the boxes). On average, solutions of Howe type have lower EI followed by Warren and Pratt types. With regard to the mass, the median is within a range between $620 \mathrm{~kg}$ and $650 \mathrm{~kg}$. Solutions of type Howe have the highest median in terms of RR, followed by Warren and Pratt types. This means that for the majority of the simulated stocks, the Howe and Warren truss type are more suitable than the Pratt truss type in terms of reuse. For the Pratt truss, stock element cross-sections and lengths did not fit well. This is also indicated by the highest infeasibility rate (75\%) of the Pratt truss when a $100 \%$ RR is imposed. 
The average computation time for convergence, recorded on an Intel i7-6820HQ 2.70 GHz CPU, per stock and truss type is $21 \mathrm{~s}, 40 \mathrm{~s}$ and $32 \mathrm{~s}$ for the Howe, Pratt and Warren truss with unconstrained RR, and 13s, 21s and 20s when an RR of $100 \%$ is imposed. When the RR is bounded, the solution space reduces and thus computation time for convergence decreases.

\subsection{Parameter study}

This section studies the influence of LCA- and stock-related parameters. Each selected parameter is varied within a certain range. The optimization process is carried out for each parameter. The same 100 randomly generated stocks as in section 4.3 are investigated for each truss type and parameter value.

\subsubsection{LCA-related parameters}

In this section, the transport distance $d_{R e u}$ from the deconstruction site to the reconditioning workshop as well as the impact factors for deconstruction $E I^{D C}$ and steel production $E I^{P r}$ are varied. The optimization process is carried out without bounding the RR.

The boxplot in Figure 16 shows the variation of EI (a), M (b) and RR (c) against $d_{\text {Reu }}$, which is varied between 0 and $5000 \mathrm{~km}$. Each boxplot contains 300 data points (100 stocks per truss type). The upper bound of $5000 \mathrm{~km}$ is set to evaluate the importance of long transport distances. For comparison, the transport distances of the stock elements assumed in section 4.2 are marked by a grey stripe between 100 and $250 \mathrm{~km}$.

As expected, the structure EI increases when the transport distance $d_{R e u}$ increases. From 0 to $500 \mathrm{~km}$ the median EI increases approximately linearly from 37 to 43 ReCiPe points and the median RR decreases from $91 \%$ to $85 \%$. For a transport distance higher than $500 \mathrm{~km}$, the EI asymptotically reaches that of structures made of new elements only $(\mathrm{RR}=0 \%$ ). For distances larger than $2000 \mathrm{~km}$ the median $\mathrm{RR}$ drops below $50 \%$ and thus integrating reused elements in the truss is not clearly beneficial. 

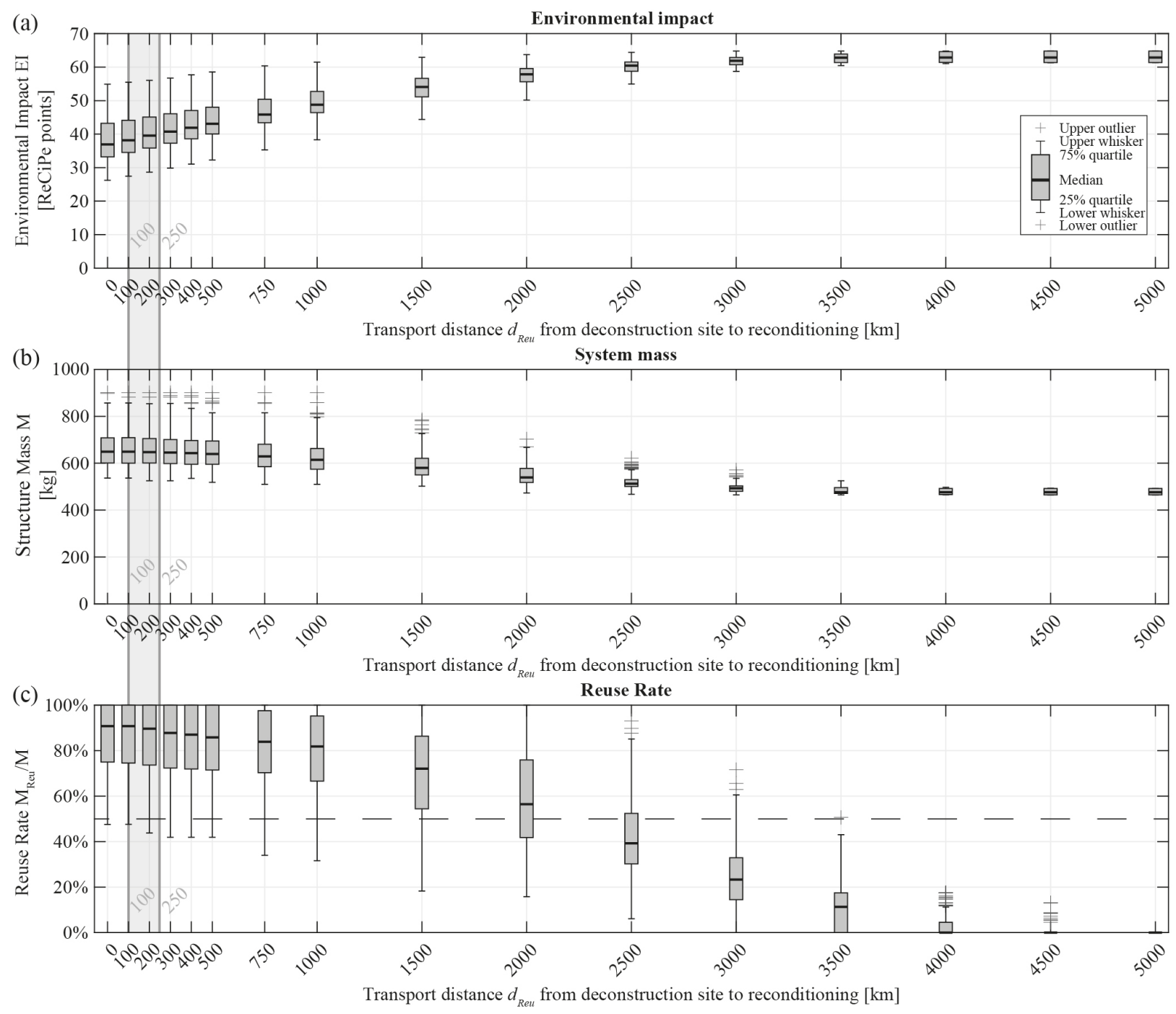

Figure 16: (a) Environmental impact (EI), (b) mass (M) and (c) reuse rate (RR) vs transport distance $d_{\text {Reu }}$ (deconstruction site to reconditioning workshop)

The deconstruction environmental impact $E I^{D C}$ depends mostly on the use of machinery employed for opening connections, hoisting, preparing and loading elements (see process map in Fig. 3). The box plots in Figure 17 shows the variation of $\mathrm{EI}(\mathrm{a}), \mathrm{M}(\mathrm{b})$ and $\mathrm{RR}$ (c) against $E I^{D C}$ which is varied in a range from 0 to $0.12 \mathrm{ReCiPe}$ points $/ \mathrm{kg}$ of reclaimed steel. For comparison with previous simulations (sections 4.2 and 4.3), the reference value of $E I^{D C}=0.0186 \mathrm{ReCiPe}$ points $/ \mathrm{kg}$ is indicated by a continuous line. For $E I^{D C}$ values smaller than $0.04 \mathrm{ReCiPe}$ points $/ \mathrm{kg}$, the structure median EI increases approximately linearly as the $E I^{D C}$ increases. For $E I^{D C}$ values larger than 0.04 , the solutions asymptotically approach those made of new elements only $(\mathrm{RR}=0 \%)$. The median reuse rate decreases to zero for an $E I^{D C}$ larger than or equal to 0.09 . New production contributes more effectively than reuse to reduce the structure $\mathrm{EI}$ (median $\mathrm{RR}<50 \%$ ) only when the $E I^{D C}$ is larger than $0.055 \mathrm{ReCiPe}$ points $/ \mathrm{kg}(\sim 3$ times the reference value). Therefore, the impact of the truss should be studied case by case, after an estimation of the impact of deconstruction. 

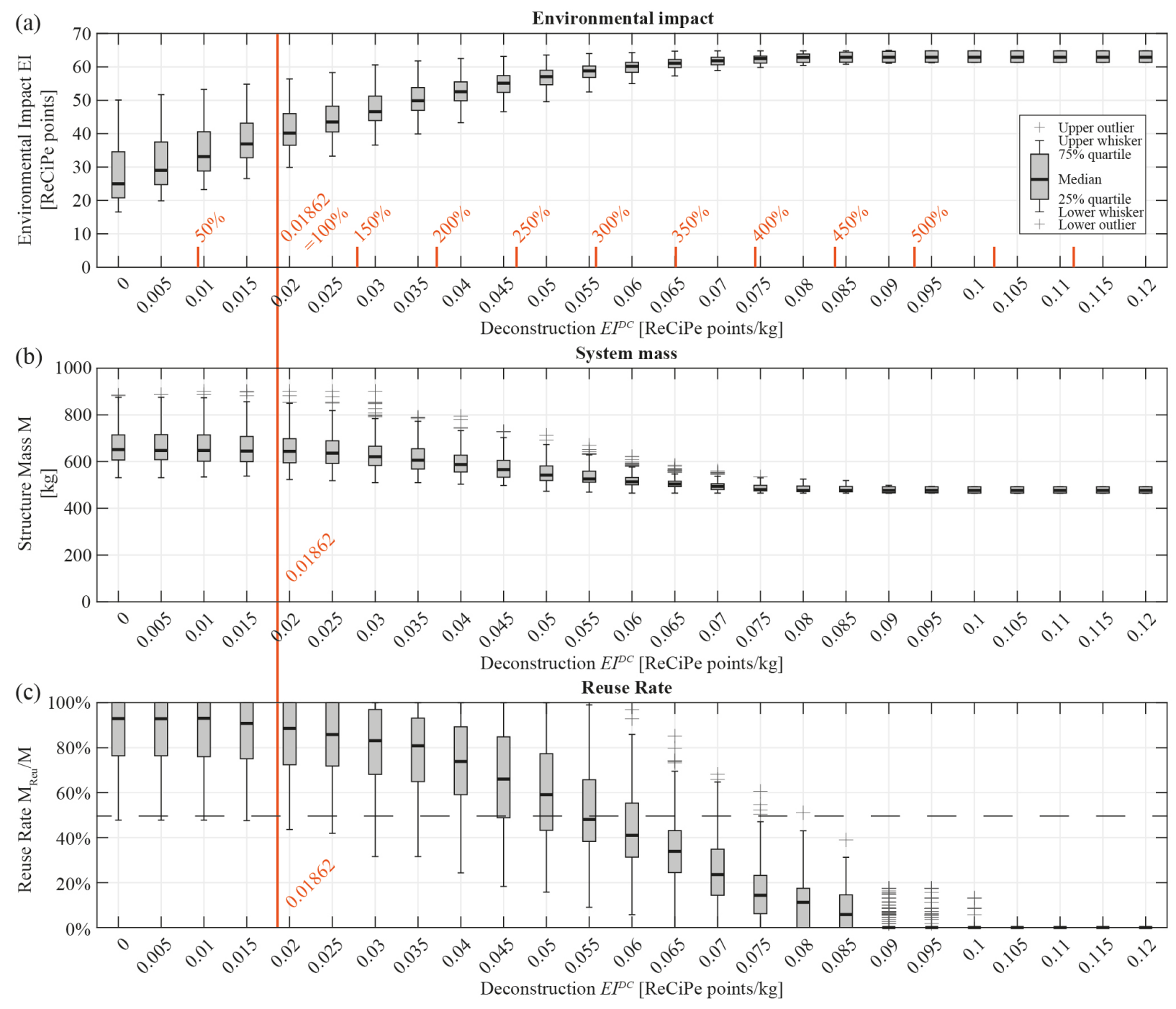

Figure 17: (a) Environmental impact (EI), (b) mass (M) and (c) reuse rate (RR) vs deconstruction impact EI $I^{D C}$

An impact factor for recycled steel production $E I^{S p}$ of $0.0718 \mathrm{ReCiPe}$ points $/ \mathrm{kg}$ was employed in previous simulations (sections 4.2. and 4.3). The boxplots in Figure 18 show the variation of EI (a), M (b) and RR (c) against $E I^{S p}$ which is varied between 0 and 0.12 ReCiPe points $/ \mathrm{kg}$. For $E I^{S p}<0.05$, the median RR increases from $18 \%$ to $82 \%$ with increasing $E I^{S p}$. Only for $E I^{S p}<0.015 \mathrm{ReCiPe}$ points $/ \mathrm{kg}$, the median RR is less than $50 \%$. In other words, reuse is more effective to reduce the structure EI even when steel production is of very low impact. Note that the value of $E I^{S p}=0.0718 \mathrm{ReCiPe}$ points $/ \mathrm{kg}$ is one of the lowest steel production impacts listed in ecoinvent 3.1 [41]. The maxima in the EI boxplots (upper whiskers) increase with $E I^{S p}$ because for some stocks it is required to assign high-impact steel elements since no other suitable element for reuse are available. 

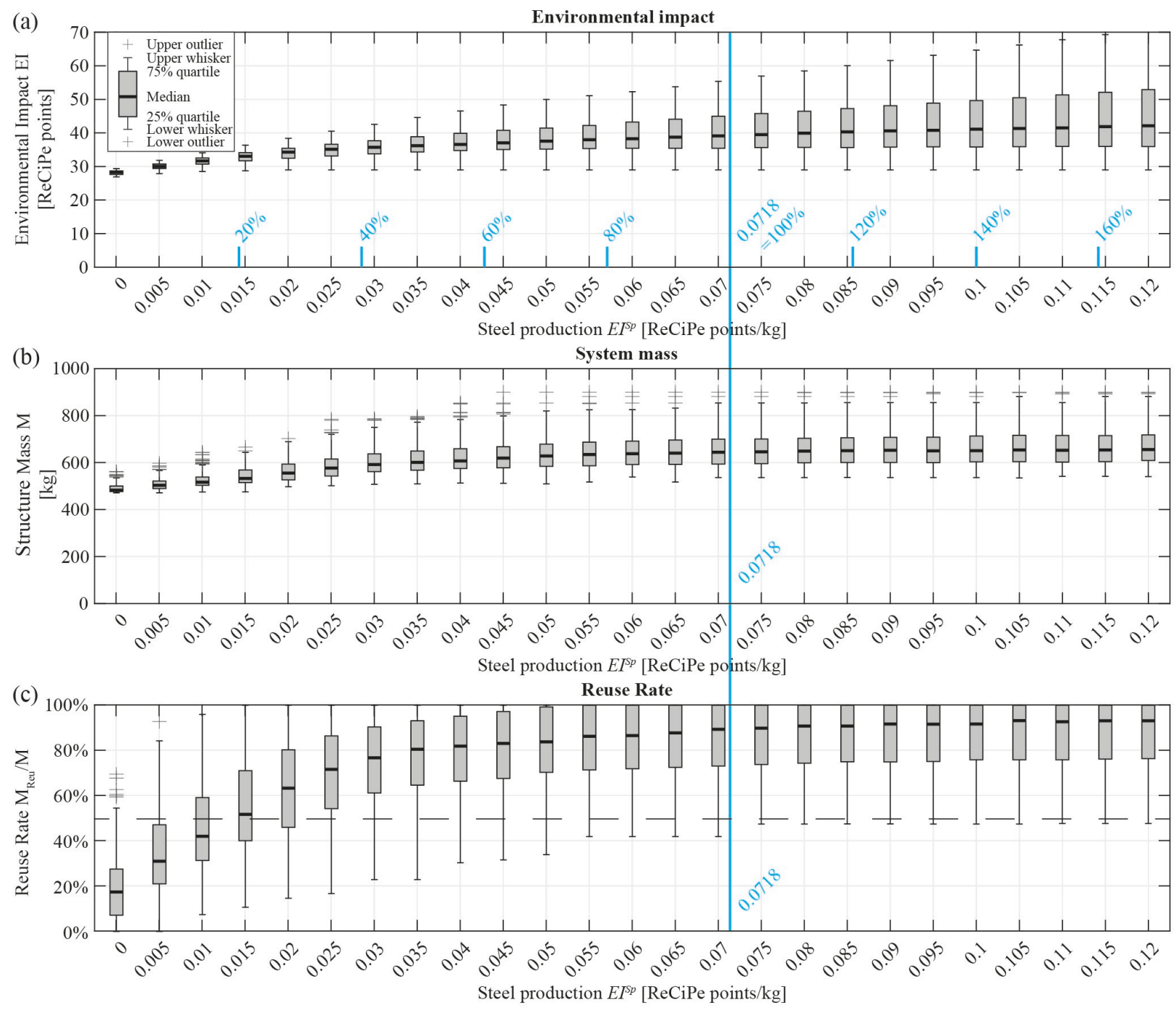

Figure 18: (a) Environmental impact (EI), (b) mass (M) and (c) reuse rate (RR) vs recycled steel production impact $E I^{S p}$

As shown by the parametric study given in this section, depending on the parameters, solutions with high reuse rate are not always the most effective to reduce the structure EI.

\subsubsection{Stock- and structure-related assumptions}

This section evaluates the influence of stock element availability and the integration of fabrication related constraints (see section 4.1). In section 4.2, the stock was defined by randomly discarding 4 of the 13 available stock element types. In this study, the number of discarded types varies from 0 (i.e. a very large stock) to 13 (i.e. an empty stock). The boxplots in Figure 19 show the variation of EI (a), M (b) and RR (c) against the number of element types in the stock. As expected, the structure EI increase when the stock contains fewer types. For stocks with 13 to 7 element types, the median EI remains below $42 \mathrm{ReCiPe}$ points and the median RR is above $80 \%$. Generally, stocks with limited availability of elements types are restrictive and therefore the structure EI tends to increase in those cases. However, in some cases, even with a 
limited element availability, solutions with a very low EI have been obtained (lower outliers (+) in Figure 19(a)). Note that the overall minimum EI solution 1) detailed in section 4.3 uses only three of the nine available stock element types.
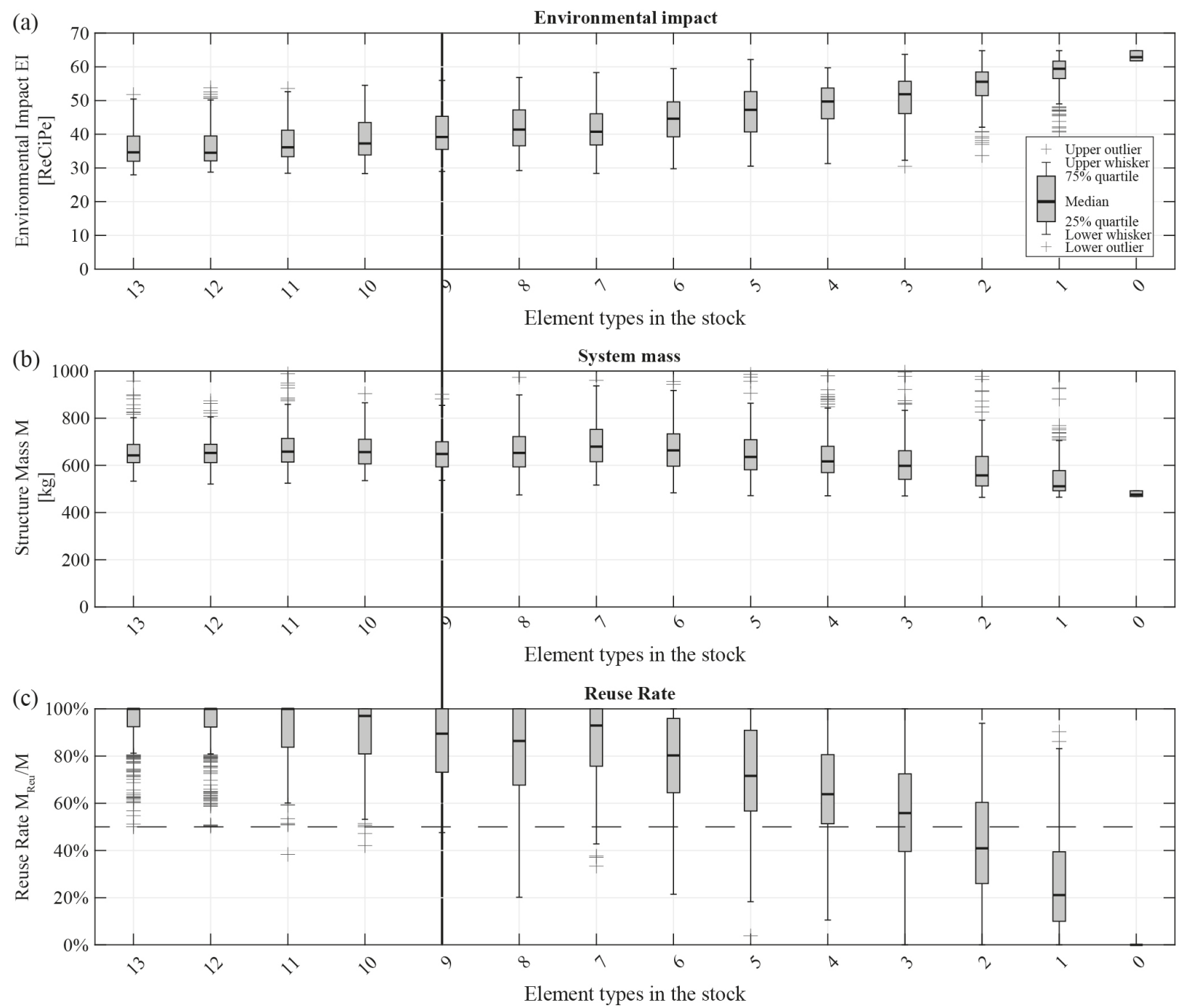

Figure 19: (a) Environmental impact (EI), (b) mass (M) and (c) reuse rate (RR) vs available number of element types in the stock

In section 4.1 fabrication related constraints have been introduced to narrow the solution space in order to obtain optimal structures which are feasible for fabrication. By removing these constraints, solutions with a lower EI and mass can be achieved, as shown by the boxplots in Figure 20. The influence of fabrication constraints is marginal for structures made from new elements only $(\mathrm{RR}=0 \%)$. For systems with reused elements solutions with lower EI and mass are obtained when no fabrication constraint exists. In addition, the removal of fabrication constraints increases the feasibility rate from 140 to 215 out of 300 solutions when the reuse rate (RR) is constrained to $100 \%$. On the other hand, it might be preferred to keep fabrication constraints to ease the manufacturing of the trusses, with a marginal increase in EI and mass. 

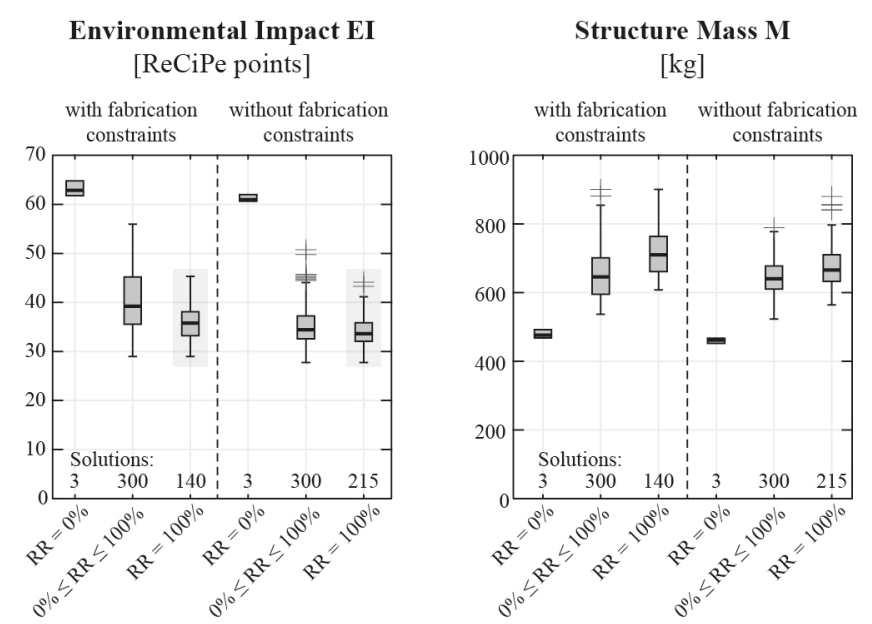

Figure 20: (a) Environmental impact (EI), (b) mass (M) with and without fabrication constraints

\section{Discussion}

The method developed in this paper led to a complete benchmarking of reuse rates for minimum EI solutions applied to three given truss types and 100 randomly-generated stocks. The study led to a better understanding of how parameters like transport distance, deconstruction processes, and stock variability influence the solution space. However, the conclusions may be limited to the selected structural systems or be affected by the boundaries of the random stock generation. Future work should expand the application of the method to more cases.

The optimization method has been formulated as a mixed-integer linear programming (MILP) problem, which gives solutions that are global optima. This way, it was possible to carry out a precise benchmarking and parameter study. However, to obtain a MILP formulation all terms of the objective and constraint functions must be expressed as linear equations, which may be a limitation of the proposed method.

The optimization method does not include the structural design of joints. Van Mellaert et al. [45] have shown detailed connection design in MILP-based structural optimization. A similar integration to this formulation could be subject of future work. This formulation could be also extended to geometry optimization, as done in Brütting [12]. In addition, the structural optimization method is not only applicable to truss structures but also to frames. Other materials like timber elements could also be considered. As shown in section 4.3.2, globally optimal solutions are obtained within a reasonable time. Henceforth, the method can be applied to optimize multiple user-defined structure layouts.

The life cycle assessment (LCA) carried out in this work is more comprehensive with respect to previous work [13]. The proposed method focuses on data processing rather than data collection. Its reliability depends on the quality of the LCA data, yet data source quality has not been methodically evaluated in this work. 


\section{Conclusion}

The optimization method presented in this work produces least environmental impact structures of reused and new elements to a structural system. The environmental impact is determined through a life cycle assessment (LCA), which has been integrated in the objective function of the structural optimization process. The structural optimization takes into account strength as well as serviceability constraints. The 'ReCiPe' impact assessment method is employed to quantify all environmental impacts from sourcing elements over manufacturing to assembling the structure.

The method has been applied for three different truss types subject to 100 randomly generated stocks. Depending on stock availability, a combination of reused and new elements is effective to produce least environmental impact structures. Generally, the EI decreases as the reuse rate increases, although high reuse rates might result in oversized structures. For the structures considered in this work, those made from reused elements have an environmental impact which is up to $56 \%$ lower compared to minimum-weight solutions made of new steel elements.

A parameter study shows that environmental impact savings through integrating a majority of reused elements are obtained even for long transport distances of stock elements. Future studies should apply the proposed method for instance to a realistic case study with a given stock of available elements, base the employed LCA on measured data and might extend the method to other objectives, e.g. financial costs.

\section{Acknowledgements}

Camille Vandervaeren is an SB-PhD fellow at Fonds Wetenschappelijk Onderzoek - Vlaanderen (FWO).

\section{References}

[1] International Energy Agency, "Material efficiency in clean energy transitions," Paris, 2019.

[2] Eurostat, "Waste statistics," 2016. [Online]. Available: https://ec.europa.eu/eurostat/statisticsexplained/index.php/Waste_statistics\#Total_waste_generation. [Accessed: 13-Jul-2019].

[3] IEA and UN Environment Programme, "2018 Global Status Report: towards a zero-emission, efficient and resilient buildings and construction sector.," 2018.

[4] R. J. Cole and P. C. Kernan, "Life-cycle energy use in office buildings," Build. Environ., vol. 31, no. 4, pp. 307$317,1996$.

[5] S. Kaethner and J. Burridge, "Embodied CO2 of structural frames," Struct. Eng., vol. 90, no. 5, pp. 33-40, 2012.

[6] M. Pongiglione and C. Calderini, "Sustainable Structural Design: Comprehensive Literature Review," J. Struct. Eng., vol. 142, no. 12, p. 04016139 , Dec. 2016.

[7] B. Addis, Building with reclaimed components and materials: a design handbook for reuse and recycling. Earthscan, 2006.

[8] J. Allwood et al., "Conserving our metal energy," Univ. Camb., 2010.

[9] M. Gorgolewski, Resource Salvation: The Architecture of Reuse. John Wiley \& Sons, 2017.

[10] W. R. Stahel, "Policy for material efficiency - sustainable taxation as a departure from the throwaway society," Phil Trans R Soc A, vol. 371, no. 1986, p. 20110567, Mar. 2013.

[11] M. Gorgolewski, "Designing with reused building components: some challenges," Build. Res. Inf., vol. 36, no. 2, pp. 175-188, 2008.

[12] J. Brütting, J. Desruelle, G. Senatore, and C. Fivet, "Design of Truss Structures Through Reuse,” Structures, vol. 18, pp. 128-137, Apr. 2019. 
[13] J. Brütting, G. Senatore, and C. Fivet, "Optimization Formulations for the Design of Low Embodied Energy Structures Made from Reused Elements," in Advanced Computing Strategies for Engineering, vol. 10863, I. F. C. Smith and B. Domer, Eds. Cham: Springer International Publishing, 2018, pp. 139-163.

[14] M. Pongiglione and C. Calderini, "Material savings through structural steel reuse: A case study in Genoa," Resour. Conserv. Recycl., vol. 86, pp. 87-92, May 2014.

[15] J. M. Allwood and J. M. Cullen, Sustainable materials: with both eyes open. UIT Cambridge Cambridge, 2012.

[16] J. Brütting, C. De Wolf, and C. Fivet, "The reuse of load-bearing components," IOP Conf. Ser. Earth Environ. Sci., vol. 225, p. 012025 , Feb. 2019.

[17] M. Sansom and N. Avery, "Briefing: Reuse and recycling rates of UK steel demolition arisings," Proc. Inst. Civ. Eng. - Eng. Sustain., vol. 167, no. 3, pp. 89-94, Jun. 2014.

[18] D. Densley Tingley, S. Cooper, and J. Cullen, "Understanding and overcoming the barriers to structural steel reuse, a UK perspective,” J. Clean. Prod., vol. 148, pp. 642-652, Apr. 2017.

[19] C. F. Dunant, M. P. Drewniok, M. Sansom, S. Corbey, J. M. Allwood, and J. M. Cullen, "Real and perceived barriers to steel reuse across the UK construction value chain," Resour. Conserv. Recycl., vol. 126, pp. 118-131, Nov. 2017.

[20] D. Ness, J. Swift, D. C. Ranasinghe, K. Xing, and V. Soebarto, "Smart steel: new paradigms for the reuse of steel enabled by digital tracking and modelling," J. Clean. Prod., vol. 98, pp. 292-303, Jul. 2015.

[21] L. M. Luscuere, "Materials Passports: Optimising value recovery from materials," in Proceedings of the Institution of Civil Engineers-Waste and Resource Management, 2016, vol. 170, pp. 25-28.

[22] E. Iacovidou and P. Purnell, "Mining the physical infrastructure: Opportunities, barriers and interventions in promoting structural components reuse," Sci. Total Environ., vol. 557-558, pp. 791-807, Jul. 2016.

[23] Y. Fujitani and D. Fujii, "Optimum structural design of steel plane frame under the limited stocks of members," in Proceedings of the RILEM/CIB/ISO International Symposium, Integrated Life-Cycle Design of Materials and Structures, 2000, pp. 198-202.

[24] A. Bukauskas, P. Shepherd, P. Walker, B. Sharma, and J. Bregula, "Form-Fitting strategies for diversity-tolerant design," in IASS Annual Symposium 2017, 2017.

[25] D. R. Cooper and T. G. Gutowski, “The Environmental Impacts of Reuse: A Review,” J. Ind. Ecol., vol. 21, no. 1, pp. 38-56, Feb. 2017.

[26] J. Yeung, S. Walbridge, C. Haas, and R. Saari, "Understanding the total life cycle cost implications of reusing structural steel,” Environ. Syst. Decis., vol. 37, no. 1, pp. 101-120, Mar. 2017.

[27] K. Allacker, F. Mathieux, D. Pennington, and R. Pant, "The search for an appropriate end-of-life formula for the purpose of the European Commission Environmental Footprint initiative," Int. J. Life Cycle Assess., vol. 22, no. 9, pp. 1441-1458, Sep. 2017.

[28] CEN, "EN 159782011 Sustainability of construction works - Assessment of environmental performance of buildings - Calculation method." European Committee for Standardization, 2011.

[29] ISO, "ISO 14040-0 Environmental management - Life cycle assessment - Principles and framework." International Organisation for Standardisation, 2006.

[30] EC JRC IES, International Reference Life Cycle Data System (ILCD) Handbook - General guide for Life Cycle Assessment - Detailed guidance. Luxembourg: Publications Office of the European Union, 2010.

[31] M. Buyle, J. Braet, and A. Audenaert, "Life cycle assessment in the construction sector: A review," Renew. Sustain. Energy Rev., vol. 26, pp. 379-388, Oct. 2013.

[32] R. Frischknecht, "LCI modelling approaches applied on recycling of materials in view of environmental sustainability, risk perception and eco-efficiency," Int. J. Life Cycle Assess., vol. 15, no. 7, pp. 666-671, Aug. 2010.

[33] N. Huberman, D. Pearlmutter, E. Gal, and I. A. Meir, "Optimizing structural roof form for life-cycle energy efficiency," Energy Build., vol. 104, pp. 336-349, Oct. 2015.

[34] N. C. Brown and C. T. Mueller, "Design for structural and energy performance of long span buildings using geometric multi-objective optimization," Energy Build., vol. 127, pp. 748-761, Sep. 2016.

[35] M. Goedkoop, R. Heijungs, and M. Huijbregts, "ReCiPe 2008 A life cycle impact assessment method which comprises harmonised category indicators at the midpoint and the endpoint level - First edition (version 1.08) Report I: Characterisation," May 2013.

[36] G. L. Nemhauser and L. A. Wolsey, Integer programming and combinatorial optimization. Wiley, 1988.

[37] Gurobi Optimization, LLC, Gurobi Optimizer Reference Manual. 2019.

[38] Gordon Engineering, "Demolition Energy Analysis of Office Building Structural Systems," Athena Sustainable Materials Institute, Ottawa, 1997.

[39] C. F. Dunant, M. P. Drewniok, M. Sansom, S. Corbey, J. M. Cullen, and J. M. Allwood, "Options to make steel reuse profitable: An analysis of cost and risk distribution across the UK construction value chain," J. Clean. Prod., vol. 183, pp. 102-111, May 2018.

[40] PRé Consultants, Simapro. The Netherlands: PRé Consultants.

[41] G. Wernet, C. Bauer, B. Steubing, J. Reinhard, E. Moreno-Ruiz, and B. Weidema, "The ecoinvent database version 3 (part I): overview and methodology," Int. J. Life Cycle Assess., vol. 21, no. 9, pp. 1218-1230, Sep. 2016. 
[42] Thinkstep, GaBi ts 9. 2019.

[43] L. R. Millman and J. W. Giancaspro, "Environmental Evaluation of Abrasive Blasting with Sand, Water, and Dry Ice," Int. J. Archit. Eng. Constr., vol. 1, no. 3, pp. 174-182, Sep. 2012.

[44] CEN, "EN 10210-2 Hot finished steel structural hollow sections. Part 2: Tolerances, dimensions and sectional properties." European Committee for Standardization, 2019.

[45] R. Van Mellaert, G. Lombaert, and M. Schevenels, "Global Size Optimization of Statically Determinate Trusses Considering Displacement, Member, and Joint Constraints," J. Struct. Eng., vol. 142, no. 2, p. 04015120, Feb. 2016. 


\section{Appendix}

\section{Appendix A: Ecoinvent 3.1 processes}

Table A1 gives information regarding names and properties of all datasets taken from Ecoinvent 3.1 [41] which are used in this paper (see also Section 3.3).

Table A1: Names and description of datasets from Ecoinvent 3.1used in this article

\begin{tabular}{|c|c|c|c|}
\hline & $\begin{array}{l}\text { Process } \\
\text { code }\end{array}$ & Process name & Ecoinvent 3.1 data \\
\hline \multirow[t]{4}{*}{ Demolition } & DM & & \\
\hline & $\mathrm{De}$ & Demolition & $\begin{array}{l}\text { Machine operation, diesel, }>=74.57 \mathrm{~kW} \text {, steady-state }\{\mathrm{GLO}\} \mid \text { machine operation, } \\
\text { diesel, }>=74.57 \mathrm{~kW} \text {, steady-state } \mid \text { Alloc Def, S }\end{array}$ \\
\hline & $\operatorname{Pr}$ & Preparation & $\begin{array}{l}\text { Machine operation, diesel, }>=74.57 \mathrm{~kW} \text {, steady-state }\{\mathrm{GLO}\} \mid \text { machine operation, } \\
\text { diesel, }>=74.57 \mathrm{~kW} \text {, steady-state } \mid \text { Alloc Def, } \mathrm{S}\end{array}$ \\
\hline & Lo & Loading & $\begin{array}{l}\text { Machine operation, diesel, }>=74.57 \mathrm{~kW} \text {, steady-state }\{\mathrm{GLO}\} \mid \text { machine operation, } \\
\text { diesel, }>=74.57 \mathrm{~kW} \text {, steady-state } \mid \text { Alloc Def, S }\end{array}$ \\
\hline \multirow[t]{3}{*}{ Production } & $\mathbf{P}$ & & \\
\hline & $\mathrm{Sp}$ & Steel production & Steel, low-alloyed $\{\mathrm{RER}\} \mid$ steel production, electric, low-alloyed $\mid$ Alloc Def, U \\
\hline & $\mathrm{Hr}$ & Hot rolling & Hot rolling, steel $\{$ RER $\} \mid$ processing $\mid$ Alloc Def, $S$ \\
\hline \multirow[t]{5}{*}{ Deconstruction } & DC & & \\
\hline & Op & Opening connectior & $\begin{array}{l}\text { s Machine operation, diesel, }>=18.64 \mathrm{~kW} \text { and }<74.57 \mathrm{~kW} \text {, steady-state }\{\mathrm{GLO}\} \mid \text { machine } \\
\text { operation, diesel, }>=18.64 \mathrm{~kW} \text { and }<74.57 \mathrm{~kW} \text {, steady-state } \mid \text { Alloc Def, S }\end{array}$ \\
\hline & Ho & Hoisting & $\begin{array}{l}\text { Machine operation, diesel, }>=18.64 \mathrm{~kW} \text { and }<74.57 \mathrm{~kW} \text {, steady-state }\{\mathrm{GLO}\} \mid \text { machine } \\
\text { operation, diesel, }>=18.64 \mathrm{~kW} \text { and }<74.57 \mathrm{~kW} \text {, steady-state } \mid \text { Alloc Def, S }\end{array}$ \\
\hline & $\operatorname{Pr}$ & Preparation & $\begin{array}{l}\text { Machine operation, diesel, }>=18.64 \mathrm{~kW} \text { and }<74.57 \mathrm{~kW} \text {, steady-state }\{\text { GLO }\} \mid \text { machine } \\
\text { operation, diesel, }>=18.64 \mathrm{~kW} \text { and }<74.57 \mathrm{~kW} \text {, steady-state } \mid \text { Alloc Def, S }\end{array}$ \\
\hline & Lo & Loading & $\begin{array}{l}\text { Machine operation, diesel, }>=18.64 \mathrm{~kW} \text { and }<74.57 \mathrm{~kW} \text {, steady-state }\{\mathrm{GLO}\} \mid \text { machine } \\
\text { operation, diesel, }>=18.64 \mathrm{~kW} \text { and }<74.57 \mathrm{~kW} \text {, steady-state } \mid \text { Alloc Def, S }\end{array}$ \\
\hline \multirow[t]{5}{*}{ Fabrication } & $\mathbf{F}$ & Total & \\
\hline & $\mathrm{Cu}$ & Cutting & Welding, arc, steel $\{$ RER $\} \mid$ processing $\mid$ Alloc Def, $U$ \\
\hline & We & Welding & Welding, arc, steel $\{$ RER $\} \mid$ processing $\mid$ Alloc Def, $U$ \\
\hline & $\mathrm{Dg}$ & Degreasing & $\begin{array}{l}\text { Degreasing, metal part in alkaline bath }\{R E R\} \mid \text { processing } \mid \text { Alloc Def, } S \text { (of project } \\
\text { Ecoinvent } 3 \text { - allocation, default - system) }\end{array}$ \\
\hline & Pc & Powder coating & $\begin{array}{l}\text { Powder coat, steel }\{\text { RER }\} \mid \text { powder coating, steel } \mid \text { Alloc Def, S (of project Ecoinvent } 3 \text { - } \\
\text { allocation, default - system) }\end{array}$ \\
\hline \multirow[t]{2}{*}{ Assembly } & $\mathbf{A}$ & & \\
\hline & Ho & Hoisting & $\begin{array}{l}\text { Machine operation, diesel, }>=18.64 \mathrm{~kW} \text { and }<74.57 \mathrm{~kW} \text {, steady-state }\{\mathrm{GLO}\} \mid \text { machine } \\
\text { operation, diesel, }>=18.64 \mathrm{~kW} \text { and }<74.57 \mathrm{~kW} \text {, steady-state } \mid \text { Alloc Def, S }\end{array}$ \\
\hline Transport & $\mathbf{T}$ & Transport by truck & Transport, freight, lorry 16-32 metric ton, EURO4 $\{\mathrm{GLO}\} \mid$ market for \\
\hline
\end{tabular}

\section{Appendix B: Fabrication constraints}

Fabrication constraints have been introduced in section 4.1 to rationalize the optimal structures for fabrication. For the Howe truss, top chord member pairs 9/10, 11/12 and 13/14 (member indices in Figure 4) are constrained to be cut out from the same stock element (cutting-stock). The same applies to element pairs 9/10,11/12, 13/14 and 15/16 in case of the Pratt truss and for pairs 11/12 and 14/15 in case of the Warren truss. Equivalently, if these members are newly produced, their cross-sections are constrained to be identical pairwise as for the reuse case. The Howe and Pratt truss bottom chord members $1 / 2,3$ to 6 , and $7 / 8$ are required to have the same outer cross-section width to avoid discontinuities that would make joint fabrication more complex. However, a difference in wall thickness is allowed. For the same reason, the width difference between Howe truss members $2 / 3,6 / 7,10 / 11$ and $12 / 13$ is restricted to be within $\pm 10 \mathrm{~mm}$. For the Pratt and the Warren truss the width difference is similarly restricted between members $2 / 3,6 / 7,10 / 11,14 / 15$ and members 10/11, 15/16 for each truss respectively. 


\section{Appendix C: Howe and Warren truss optimal assignment}

Figures $\mathrm{C} 1$ and $\mathrm{C} 3$ show the optimal element assignment for the Howe and Pratt truss for the stock configuration considered in section 4.2. Elements from new production are represented in blue and reused elements in black. Labels give the member index and the element assignment. Metrics for each case (New, Optimal and Reuse) are given in Table 3.

(a) Howe New $R R=0 \% \quad E I=62.9$

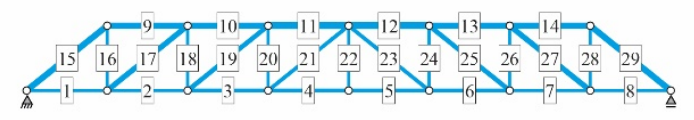

(b) Howe Optimal $R R=93 \% E I=36.6$
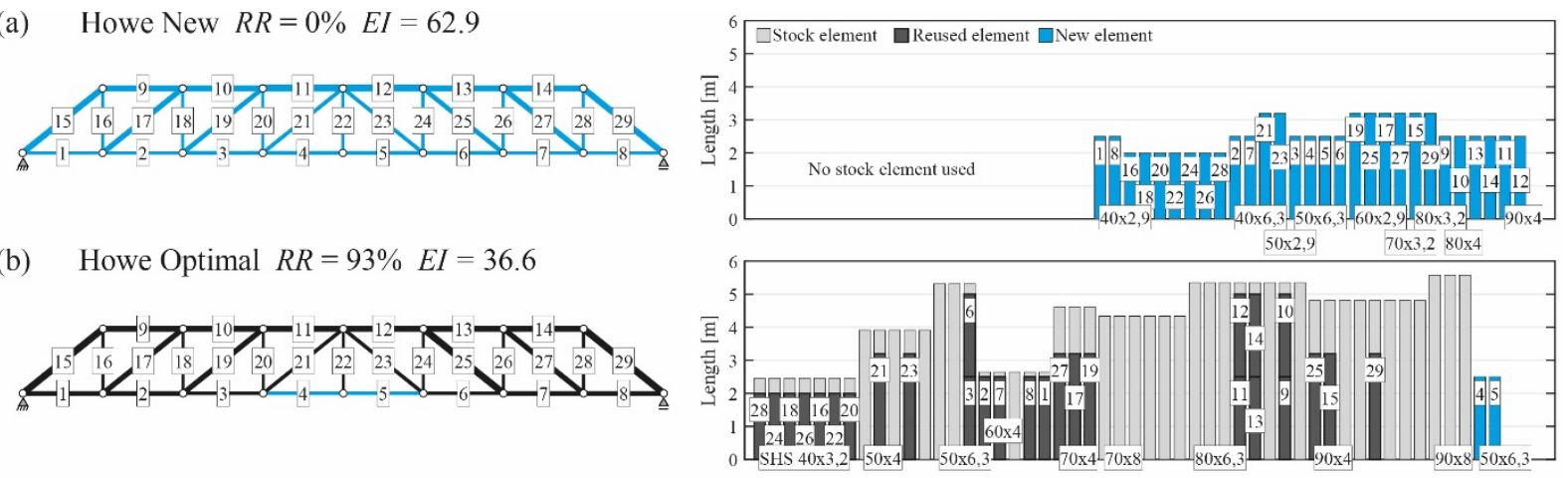

(c) Howe Reuse $R R=100 \% \quad E I=38.0$
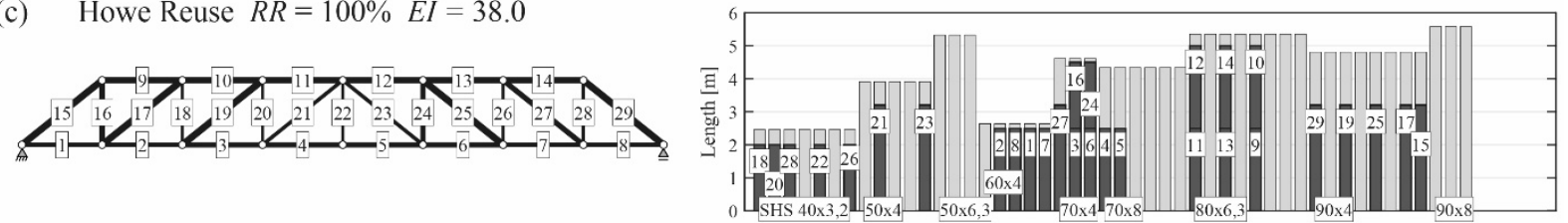

Figure C1: Optimal assignment for Howe truss

(a) Warren New $R R=0 \% \quad E I=61.4$
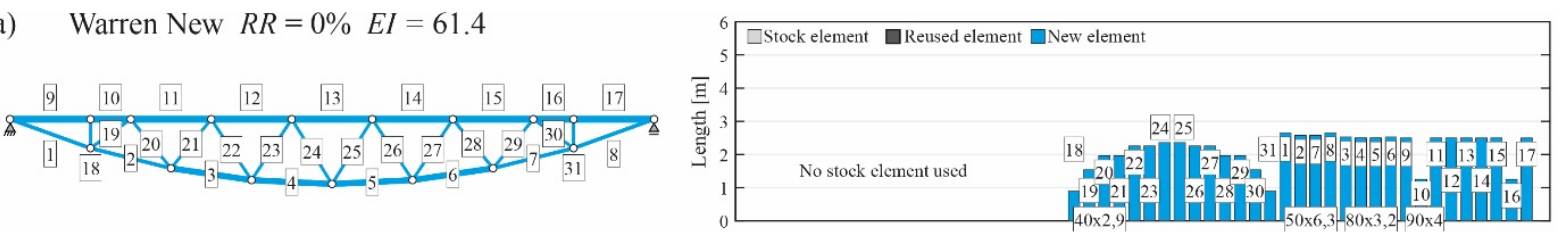

(b) Warren Optimal $R R=100 \% E I=31.5$
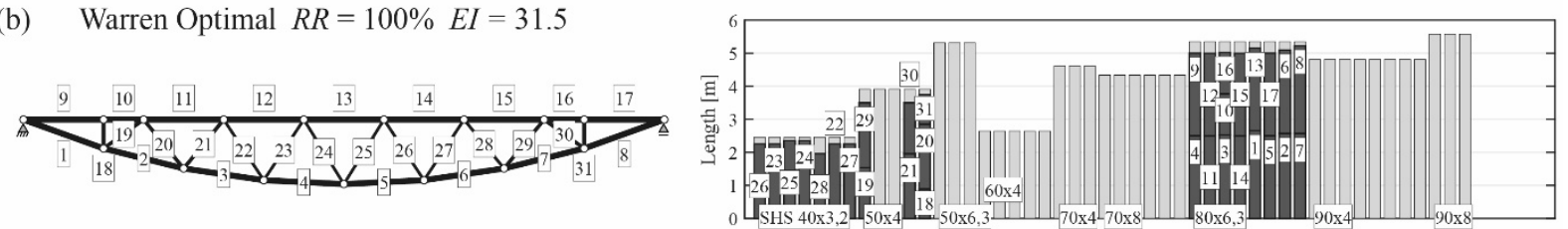

(c) Warren Reuse $R R=100 \% E I=31.5$
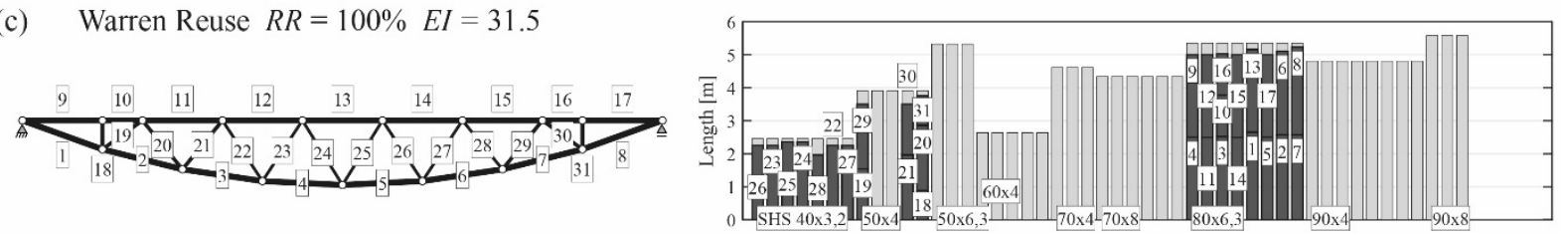

Figure C2: Optimal assignment for Warren truss

\section{Appendix D: 1-1 Assignment vs Cutting-stock}

The structural optimization method outlined in this paper extends previous work [13] with a formulation that allows the use of one stock element for multiple member assignments (cutting-stock, see section 0). The box plots in Figure D1 shows the variation of the structure EI for three truss types (Howe, Pratt and Warren) described in section 4.1. Each boxplot contains 100 randomly generated stocks per truss type. Two assignment formulations are compared: A) the 1-to- 
1 assignment i.e. an element from the stock can only be assigned to one position in the structure and B) multiple members can be assigned from one stock elements (cutting-stock). On average, when the cutting-stock formulation is employed, the structure EI reduces because more combinations of stock element uses are possible. However, solutions obtained through the cutting-stock formulation tend to have a slightly larger mass compared the solutions obtained through the 1to-1 assignment. This slight oversizing of cutting-stock solutions however comes with a large increase in RR, which in turn results in the reduced EI.
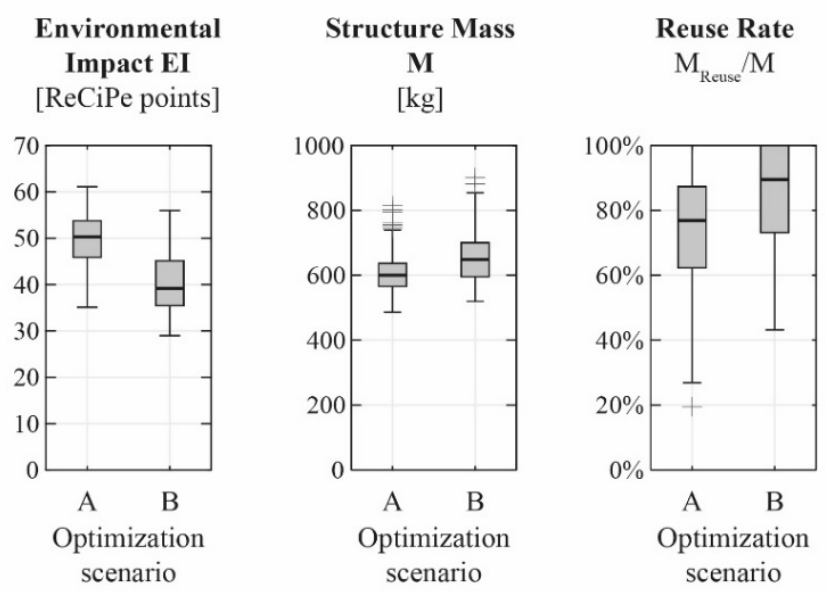

Figure D1: Environmental impact (EI), mass (M) and reuse rate (RR); 1-to-1 element assignment vs with the cutting-stock 